\title{
A Neuronal Isoform of Protein Kinase G Couples Mitogen-Activated Protein Kinase Nuclear Import to Axotomy-Induced Long-Term Hyperexcitability in Aplysia Sensory Neurons
}

\author{
Ying-Ju Sung, ${ }^{1}$ Edgar T. Walters, ${ }^{2}$ and Richard T. Ambron ${ }^{1}$ \\ ${ }^{1}$ Department of Anatomy and Cell Biology, Columbia University, New York, New York 10032, and ${ }^{2}$ Department of Integrative Biology, Physiology, and \\ Pharmacology, University of Texas, Houston, Texas 77030
}

\begin{abstract}
The induction of a long-term hyperexcitability (LTH) in vertebrate nociceptive sensory neurons (SNs) after nerve injury is an important contributor to neuropathic pain in humans, but the signaling cascades that induce this LTH have not been identified. In particular, it is not known how injuring an axon far from the cell soma elicits changes in gene expression in the nucleus that underlie LTH. The nociceptive SNs of Aplysia (ap) develop an LTH with electrophysiological properties after axotomy similar to those of mammalian neurons and are an experimentally useful model to examine these issues. We cloned an Aplysia PKG (cGMP-dependent protein kinase; protein kinase $\mathrm{G}$ ) that is homologous to vertebrate type-I PKGs and found that apPKG is activated at the site of injury in the axon after peripheral nerve crush. The active apPKG is subsequently retrogradely transported to the somata of the SNs, but apPKG activity does not appear in other neurons whose axons are injured. In the soma, apPKG phosphorylates apMAPK (Aplysia mitogen-activated protein kinase), resulting in its entry into the nucleus. Surprisingly, studies using recombinant proteins in vivo and in vitro indicate that apPKG directly phosphorylates the threonine moiety in the T-E-Y activation site of apMAPK when the -Y- site contains a phosphate. We used inhibitors of nitric oxide synthase, soluble guanyl cyclase, or PKG after nerve injury, and found that each prevented the appearance of the LTH. Moreover, blocking apPKG activation prevented the nuclear import of apMAPK. Consequently, the nitric oxide-PKG-MAPK pathway is a potential target for treatment of neuropathic pain.
\end{abstract}

Key words: chronic pain; positive injury signal; nitric oxide; nerve injury; cGMP; retrograde transport

\section{Introduction}

Persistent neuropathic pain is a major clinical problem that has mostly resisted effective treatment. In humans (Gracely et al., 1992) and mammalian model systems (Millan, 1999), persistent pain after nerve injury is associated with a long-term hyperexcitability (LTH) of sensory neurons (SNs) having axons in the injured nerve. LTH is manifested as increased sensitivity to electrical stimuli in the SN cell body and axon at the injury site (Wall and Devor, 1983; Study and Kral, 1996; Zhang et al., 1997; Chen and Devor, 1998; Kim et al., 1998; Abdulla and Smith, 2001). These changes result in discharge of SNs at rest or during innocuous stimulation, leading to continuing excitation of higher order neurons in the CNS and to persistent pain.

Because the appearance of LTH involves alterations in gene

Received March 5, 2004; revised July 6, 2004; accepted July 8, 2004.

This work was supported by Javits National Institutes of Health Grant NS22150 and by private funds. Y.-J.S. is supported by National Institutes of Health Grant NS 35979. We thank Dr. E. R. Kandel for providing D8 antibody, Dr. M. Karin for the pGEXElk1construct, Dr. J. Kyriakis for the pGEXMEKK1-C and pGEXMEK1 constructs, and Dr. R. B. Denman for reviewing this manuscript.

Correspondence should be addressed to Dr. Ying-Ju Sung, Department of Anatomy and Cell Biology, Columbia University, New York, NY 10032. E-mail: yjs8@columbia.edu.

DOI:10.1523/JNEUROSCI.1445-04.2004

Copyright $\odot 2004$ Society for Neuroscience $\quad$ 0270-6474/04/247583-13\$15.00/0 expression (Waxman et al., 1994; Wang et al., 2002; Park et al., 2003), a central question is how such changes in the nucleus are induced by an injury that occurs far from the cell body? Answering this question has been extremely difficult using the complex mammalian nervous system. A experimentally favorable alternative is the homogeneous cluster of SNs that reside in the bilateral pleural ganglia of the mollusk Aplysia californica (Walters et al., 2004). Noxious mechanical stimulation of the body wall (Walters et al., 1983a) or crushing SN axons in vivo or in vitro, elicits an LTH with electrophysiological properties similar to those seen after axotomy of mammalian SNs (Walters et al., 1991; Walters, 1994; Ambron et al., 1996; Bedi et al., 1998; Ungless et al., 2002; Sung and Ambron, 2004). The LTH appears after a delay, suggesting that its induction after nerve crush is attributable to a positive molecular injury signal (Walters et al., 1991; Ambron and Walters, 1996; Lin et al., 2003). Two studies support this idea. First, blocking axonal transport after nerve injury in excised nervous systems prevented the appearance of LTH (Gunstream et al., 1995). Second, LTH was induced in noninjured SNs by injecting axoplasm from injured axons (Ambron et al., 1995). LTH was also elicited in the SNs after intrasomatic injection of an ERK (extracellular signal-regulated kinase) member of the MAPK (mitogen-activated protein kinase) family (Sung et al., 2000), and 
cGMP and PKG (cGMP-dependent protein kinase; protein kinase G) are probably involved (Lewin and Walters, 1999). Nevertheless, we still do not know the identity of the signal from the axon, how PKG and the ERK are activated, or how these kinases might interact. Moreover, LTH was also reported to be induced by cAMP acting on PKA (protein kinase A) in a learning paradigm (Dale et al., 1988; Scholz and Byrne, 1988), and because PKG and PKA have common properties, overlap in these pathways was a possibility. To resolve these gaps in our knowledge, we cloned an Aplysia (ap) PKG and found that the induction of LTH after nerve crush requires its activation. Activated apPKG is retrogradely transported to $\mathrm{SN}$ cell bodies, where it phosphorylates apMAPK directly, resulting in its translocation into the nucleus. This is the first report of a direct activation of apMAPK by PKG, and we speculate that this discovery will have broad implications for other long-term changes associated with axon injury.

\section{Materials and Methods}

In vivo nerve crush. Aplysia (100-150 gm) were anesthetized with isotonic $\mathrm{MgCl}_{2}$, and a small incision was made on one side of the body wall. Pedal nerves 5-9 were crushed $2 \mathrm{~cm}$ from the pedal-pleural ganglia on one side. The wound was sutured, and the animal was returned to its tank. The crush-ligation protocol followed was as described (Ambron et al., 1995).

Cloning. Degenerate oligonucleotide primers 5 '-tayaaytgyacnmgiacngc and $5^{\prime}$-ccrcaraangtccangtytt were used to amplify an apPKG cDNA fragment from Aplysia CNS cDNA. The resulting PCR product from this amplification was cloned into pCR-II (Invitrogen, Carlsbad, CA) and subsequently sequenced by the core facility at Columbia University. The $5^{\prime}$ end and $3^{\prime}$ end of the cDNA were cloned using $5^{\prime}$-rapid amplification of cDNA ends (RACE) and 3'-RACE, respectively. A Marathon cDNA Amplification kit (BD Clontech, Palo Alto, $\mathrm{CA}$ ) was used to generate cDNA from Aplysia CNS poly $\left(\mathrm{A}^{+}\right)$RNA according to the manufacturer's instructions. For the $5^{\prime}$-RACE reaction, a specific primer, $5^{\prime}$-cgcctgtccagcacccatagcg, was used. The product of this PCR reaction was then confirmed by a second amplification using a nested, specific $5^{\prime}$ primer, $5^{\prime}$-gggtgaccgctttcacggagg. For the $3^{\prime}$-RACE reaction, a specific primer, $5^{\prime}$-cggcaaggttctgcgtcgcc, was used. The PCR product was then subjected to a second amplification using a nested, $3^{\prime}$ primer, $5^{\prime}$-ggacgcgaggggatacgtc. Both $5^{\prime}$ - and $3^{\prime}$-RACE products were subcloned into PCR-II and sequenced. To obtain the fulllength cDNA in one piece, another PCR was performed with oligonucleotides $5^{\prime}$-ggtggaggagatagcggcggttctgtgaacgcc and $5^{\prime}$-ggaggagtgagggtcagatcc, corresponding to the $5^{\prime}$ and $3^{\prime}$ ends of $5^{\prime}$ - and $3^{\prime}$-RACE products, respectively. The PCR product was sequenced and designated apPKG and was deposited in the GenBank database under accession number AY362340.

Sequence analysis. Sequence alignment of various PKGs and identification of conserved residues was performed using the Clustal $\mathrm{W}$ and box-shade algorithms provided in the suite of programs available from Biology Workbench (http://workbench.sdsc.edu/).

Protein expression and purification. A His tag was added to the $\mathrm{N}$ terminus of the apPKG-coding region by PCR amplification from Aplysia CNS cDNA with the following primers: $5^{\prime}$-tggcggccgctcatgagaggatcgcatcaccatcaccatcacggcaacggtgccagttcgaacacgcacttc and $5^{\prime}$-gcaggctctagagaaatcaatgtcccagccggataactcgtc. The PCR product was subcloned into the NotI and XbaI sites of pFasBac-1 (Invitrogen) and was subsequently confirmed by sequencing. The resulting construct pFBlapcGK contains an N-terminal histidine epitope tag. Transformation of pFBlapcGK into Max Efficiency DH10Bac cells (Invitrogen), identification of recombinant clones, and isolation of the recombinant baculovirus shuttle vector DNA (bacmid) were performed according to the manufacturer's instructions (Invitrogen). Recombinant baculovirus was obtained by transfecting Sf9 cells (Spodoptera frugiperda), which were propagated as monolayers at $27^{\circ} \mathrm{C}$ in Sf-900 IISFM medium (Invitrogen) containing $100 \mathrm{U} / \mathrm{ml}$ penicillin (Invitrogen) and $0.1 \mathrm{mg} / \mathrm{ml}$ streptomycin (Invitrogen). Transfection with recombinant bacmid DNA was performed using CellFectin (Invitrogen) according to the instructions of the manufacturer. Positive viral clones were identified by their ability to direct the expression of the appropriate protein as revealed by immunoblot- ting of whole-cell extracts of transfected Sf9 cells harvested $3 \mathrm{~d}$ posttransfection using an antibody to the His tag of the protein. For apPKG protein expression, $\mathrm{Sf} 9$ cells were infected with the recombinant baculovirus at a multiplicity of infection of $>10$. After $72 \mathrm{hr}$, cells were harvested and recombinant His-apPKG was purified on nickel nitriloacetic acid resin (Qiagen, Valencia, CA) according to the manufacturer's instructions. To express VASP (vasodilator-stimulated phosphoprotein), the coding region of VASP was first obtained by PCR amplification from mouse brain cDNA with the following primers: 5 '-gtcgtgggatccccatcgatagcgagacggtcatctgt and 5 '-atcttgaattcctcgagggtcaaggagaaccccgctt. The PCR product was subcloned into the EcoRI and Bam HI sites of pGEX3X (Amersham Biosciences, Arlington Heights, IL) and was subsequently confirmed by sequencing. The resulting construct pGEXVASP contains a C-terminal GST (glutathione $S$-transferase) epitope tag. VASP-GST, Elk1-GST, MEKK1C (MAP kinase kinase kinase 1C)-GST, MEK1 (MAP kinase kinase 1)-GST, and ERK1GST fusion proteins were expressed in Escherichia coli DH5 $\alpha$ and purified as described (Sung et al., 1996).

Northern blots. Total RNA was extracted from various tissues and resolved by denaturing agarose gel electrophoresis; the gel was then transferred to a nylon membrane. The resulting blot was hybridized with radioactively labeled apPKG and $5 \mathrm{~S}$ ribosomal cDNA as described previously (Alberini et al., 1994; Sung et al., 2001).

Single-cell RT-PCR. Single SNs were transferred to $500 \mu \mathrm{l}$ of Tri Reagent (Molecular Research Center, Cincinnati, $\mathrm{OH}$ ), and total RNA was isolated according to the manufacturer's instructions. cDNA from each sample was synthesized using random hexamers as primers and reverse transcriptase (SuperScript II). Aliquots $(2 \mu \mathrm{l})$ from each sample were used to amplify specific fragments by PCR ( 40 cycles), using specific primer sets for the following: (1) neuronal nitric oxide synthase (NOS) (GenBank accession number AAK83069), 5' -gtaccctcacaggacgagtc and $5^{\prime}$-tccttggacctctcttggtg (nt 3610-4049); (2) SN-specific neuropeptide sensorin A (GenBank accession number X56770), 5' -aacagaaacagtctttcccc and $5^{\prime}$-tcttgactcaccaactgcc (nt 43-331); and (3) neuron-specific actin (GenBank accession number U01352), 5'-cagagagaagatgacccag and 5'-gggtaagagaagcaagaaag (nt 416-1298)

Kinase assays. In vitro PKG activity was measured as described (Pohler et al., 1995). Briefly, $100 \mathrm{ng}$ of His-apPKG was incubated with $5 \mu \mathrm{g}$ of various peptides in a buffer containing the following (in mM): 25 Tris$\mathrm{HCl}$, pH 7.5, $5 \beta$-glycerol phosphate, $2 \mathrm{DTT}, 0.1 \mathrm{Na}_{3} \mathrm{VO}_{4}$, and $10 \mathrm{MgCl}_{2}$. The reaction was initiated by adding $10 \mu \mathrm{M}\left[\gamma^{-32} \mathrm{P}\right] \mathrm{ATP}$. The incubation was allowed to proceed for $20 \mathrm{~min}$ at room temperature and terminated with 50 mM EDTA (final concentration). Labeled peptides were captured on P81 filters (Whatman, Maidstone, UK). The filters were washed with $0.5 \%$ phosphoric acid and dried, and the bound ${ }^{32} \mathrm{P}$-phosphopeptide was detected by liquid scintillation counting. All of the values were corrected for background counts per minute obtained without the substrate. To evaluate endogenous apPKG activity, $5 \mu \mathrm{g}$ of ganglia extract or axoplasm was used in the kinase buffer (above) with $5 \mu \mathrm{g}$ of PKA inhibitor and in the presence or absence of $1 \mu \mathrm{M}$ cGMP.

ERK activity was assayed as described (Sung et al., 2001). Briefly, proteins and $500 \mu \mathrm{M}$ ATP were incubated in kinase buffer for $20 \mathrm{~min}$ at room temperature. The reaction mixtures were resolved on $10 \%$ SDS polyacrylamide

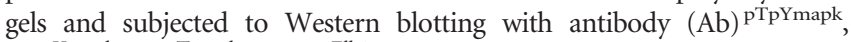
$\mathrm{Ab}^{\text {pYmapk }}, \mathrm{Ab}^{\mathrm{p}^{\text {Tmapk }}}$, or $\mathrm{Ab}^{\text {pElk1 }}$.

In situ hybridization. Ganglia were first isolated from animals, desheathed, and fixed in 4\% paraformaldehyde in PBS, pH 7.4, for $3 \mathrm{hr}$. The ganglia were then washed several times in $1 \times \mathrm{PBS}$ and then digested with $80 \mu \mathrm{g} / \mathrm{ml}$ proteinase $\mathrm{K}$ (Ambion, Austin, TX) in $1 \times$ PBS for $30 \mathrm{~min}$ at room temperature $(\mathrm{RT})$. After several washes in $1 \times \mathrm{PBS}$, the ganglia were fixed again for $20 \mathrm{~min}$ with $4 \%$ paraformaldehyde and then washed several more times in $1 \times$ PBS. After treatment with $1.32 \%$ triethanolamine $\mathrm{HCl}, \mathrm{pH} 8.0$ (10 min at $\mathrm{RT}$ ), and $0.24 \%$ acetic anhydride in $1.32 \%$ triethanolamine $\mathrm{HCl}, \mathrm{pH} 8.0$ (20 min at RT), and several washes with $1 \times$ PBS, the ganglia were prehybridized in Hyb buffer $(50 \%$ formamide, $5 \times$ SSC, $5 \times$ Denhardt's solution, $0.25 \mathrm{mg} / \mathrm{ml}$ yeast tRNA, and $0.5 \mathrm{mg} / \mathrm{ml}$ salmon sperm DNA) at $60^{\circ} \mathrm{C}$ for $2 \mathrm{hr}$, and then hybridized overnight at $60^{\circ} \mathrm{C}$ with fresh Hyb buffer containing either antisense or sense digoxigenin (DIG)-labeled cRNA $(1 \mu \mathrm{g} / \mathrm{ml})$. After hybridization, ganglia were first washed for $30 \mathrm{~min}$ in fresh Hyb buffer at $68^{\circ} \mathrm{C}$, and then in $0.2 \times$ SSC 
at $68^{\circ} \mathrm{C}$ for $1 \mathrm{hr}$. After equilibration in PBST ( $1 \times$ PBS and $0.1 \%$ Triton $\mathrm{X}-100$ ), ganglia were blocked with $10 \%$ sheep serum in PBST for $30 \mathrm{~min}$ at RT, and then incubated with anti-DIG antibody (1:5000) coupled to alkaline phosphatase (Roche, Indianapolis, IN) in $1 \times$ PBST containing $1 \%$ sheep serum overnight at $4^{\circ} \mathrm{C}$. Hybridization signals were visualized with nitroblue tetrazolium chloride/5-bromo-4-chloro-3-indolyl phosphate (Roche).

Western blotting. Protein samples were resolved on $10 \%$ SDS polyacrylamide gels and subsequently transferred onto nitrocellulose membranes (Schleicher \& Schuell, Keene, NH); the blots were probed with various gene-specific primary antibodies and appropriate horseradish peroxidase-conjugated secondary antibodies. Immunoreactivity was detected using the Pico-tag chemiluminescence system (Pierce, Rockford, IL).

Immunocytochemistry. Ganglia, nerve, or cultured cells were fixed with $4 \%$ paraformaldehyde in PBS, $\mathrm{pH} 7.4$. The primary antibody was diluted in TBS supplemented with $0.1-0.5 \%$ Triton X-100 in TBS and $5 \%$ goat serum, and incubated overnight at $4^{\circ} \mathrm{C}$. After several washes, an Alexa Fluor 594- or 488-conjugated secondary antibody (Molecular Probes, Eugene, OR) was applied for $1 \mathrm{hr}$ at room temperature. Subsequently, the cells were visualized by confocal fluorescence microscopy (LSM510 confocal microscope; Zeiss, Oberkochen, Germany), and images were collected.

Cell culture. SNs were isolated from the pleural ganglia of 50-80 gm animals and were plated on poly-L-lysine-coated dishes containing L15 medium and 50\% hemolymph (Dagan and Levitan, 1981; Glanzman et al., 1989). Cultures were maintained at $18^{\circ} \mathrm{C}$ for up to $7 \mathrm{~d}$. Medium was changed every $2 \mathrm{~d}$. Drugs were washed out $1 \mathrm{hr}$ before electrophysiological tests.

Electrophysiology. Before the start of each recording, the hemolymph was replaced with a 1:1 mixture of artificial seawater and culture medium (without hemolymph; pH 7.6). Standard techniques were used for intracellular stimulation and recording (Ambron et al., 1996). The soma spike threshold was measured with a standard series of $20 \mathrm{msec}$ depolarizing pulses. Repetitive firing was quantified by counting the number of spikes evoked by a series of $2 \mathrm{sec}$ depolarizing pulses at $1,2,3,4$, and $5 \mathrm{nA}$, or 1 sec depolarizing pulses at 2.5 times the current for the $20 \mathrm{msec}$ threshold. Spike amplitude was measured from baseline to the peak of the action potential, and spike duration was the breadth of the action potential at one-half of its maximal height.

Fluorescence protein labeling. BSA, apPKG, and ERK1 protein were labeled using an Alexa Fluor 546 Protein Labeling kit (Molecular Probes) according to the manufacturer's instructions.

SN microinjection. Microinjection pipettes were prepared with a Sutter programmable puller. Alexa Fluor 546-labeled protein $(0.75 \mu \mathrm{g} / \mu \mathrm{l}$ in 10 $\mathrm{mm}$ Tris- $\mathrm{HCl}, \mathrm{pH} 7.3,100 \mathrm{~mm} \mathrm{NaCl}$, and $0.05 \%$ fast green dye) was microinjected into cultured SNs by applying positive air pressure under defined conditions (pounds per square inch and duration) using a picospritzer (Sung et al., 2000).

Materials. Recombinant bovine PKG $1 \alpha$, guanosine 3',5'-cyclic monophosphorothioate, 8-(4-chlorophenylthio)-, Rp isomer (Rp-8pCPT-cGMPS), adenosine 3 ', 5' -cyclic monophosphorothioate, Rp isomer (Rp-cAMPS), 1-H[1,2,4] oxadiazolo[4,3-a]quinoxalin-1-one (ODQ), L-thiocitrulline, $N^{G}$-nitro-L-arginine methyl ester hydochloride (L-NAME), protein kinase A inhibitor 6-22 amide, and PKG substrate BPDEtide were purchased from Calbiochem (La Jolla, CA). Peptides A, C, and D, and MAPK p42 protein were obtained from Santa Cruz Biotechnology (Santa Cruz, CA). The following antibodies were obtained and used according to the manufacturer's instructions: anti-phospho-VASP $\left(\operatorname{Ser}^{239}\right)$ from Upstate Cell Signaling Solutions (Lake Placid, NY), polyclonal antibodies to phos-

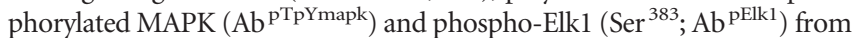

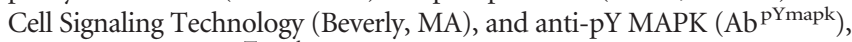
anti-pT MAPK (Ab $\left.{ }^{\text {pTmapk }^{\text {Ta }}}\right)$, and $\alpha$-actin from Sigma (St. Louis, $\mathrm{MO}$ ).

\section{Results}

\section{Aplysia SNs contain a neuronal type-I PKG}

To investigate the role of the PKG pathway in the induction of LTH, we first cloned an Aplysia PKG (GenBank accession number AY362340). ApPKG cDNA contains an open reading frame encoding a putative 733 aa protein. In concordance with all of the known PKGs, the Aplysia kinase contains two tandem cyclic nucleotide-binding domains and a C-terminal catalytic domain (Fig. $1 A$, top). The predicted protein encoded by the apPKG sequence is highly similar to known cGMP-dependent protein kinases with $>50 \%$ amino acid identity to Drosophila PKGs and to the mammalian type-I and -II PKG isoforms (Fig. $1 \mathrm{~A}$, bottom). However, it appears to be most closely related to Drosophila DG1 (Fig. 1B).

To determine the pattern of apPKG expression, we probed a Northern blot of total RNA from various tissues from the adult animals with a ${ }^{32} \mathrm{P}$-labeled 283 bp fragment corresponding to bases 209-492 of the cDNA. The probe detected a single $3.0 \mathrm{~kb}$ transcript that was expressed in ganglia, but not in muscle or the genital organs (Fig. 1C). A ${ }^{32} \mathrm{P}$-labeled probe to $5 \mathrm{~S}$ ribosomal RNA detected a $0.19 \mathrm{~kb}$ transcript in all of the tissues (Fig. 1C).

To localize the source of the message, the apPKG probe was used to generate sense and antisense riboprobes for in situ hybridization. The antisense probe detected high levels of apPKG mRNA expression in the SN cluster and in most of the neurons in the pedal and pleural ganglia (Fig. $1 D$, left panel). Negligible labeling resulted from the sense probe (Fig. $1 D$, right panel).

We then investigated the catalytic properties of apPKG by first expressing apPKG cDNA in a baculovirus/Sf9 system. An inactive His-tagged recombinant apPKG was produced when the cells were grown in the presence of serum, and a constitutively active apPKG was made when the cells were deprived of serum. Both recombinant apPKG forms were purified via affinity chromatography.

Inactive apPKG was activated by $100 \mathrm{~nm} 8$-Br-cGMP and readily phosphorylated BPDEtide, a peptide substrate for all of the type-I PKGs (Glass and Krebs, 1982) (Fig. 2A). Comparison of active apPKG with recombinant bovine type-I $\alpha$ soluble PKG showed that both kinases readily phosphorylated several PKG peptide substrates (Fig. $2 B$ ). Significantly, neither kinase phosphorylated peptide $C$, which is the preferred substrate for membrane-bound type-II PKG (Hall et al., 1999) (Fig. 2 B). We also examined the protein VASP, whose serine at position 239 is recognized specifically by type-I soluble PKGs (Smolenski et al., 1998), and found that both the bovine and Aplysia kinase phosphorylated this site (Fig. 2C). These studies establish apPKG as a member of the soluble type-I family of PKGs.

\section{ApPKG is located in axons where it is activated by nerve injury and retrogradely transported to the cell body of the SNs}

Aplysia peripheral nerves $\mathrm{p} 5-\mathrm{p} 9$ innervate the mid-body wall and tail region and contain axons of the SNs (Walters et al., 1983a,b; Billy and Walters, 1989). To determine whether apPKG is in axons, we first raised a rabbit polyclonal antibody, $\mathrm{Ab}^{\text {apPKG }}$, against a peptide located at the $\mathrm{N}$ terminus (amino acids 18-128) of the protein. $A b^{\text {apPKG }}$ was affinity purified and used to probe Western blots. $A b^{\text {apPKG }}$ recognized an 80 and $100 \mathrm{kDa}$ polypeptide in pedal and pleural ganglion extracts, but not in muscle or genital tissue as well as the affinity-purified $80 \mathrm{kDa}$ recombinant protein (Fig. 3A). We believe that the $100 \mathrm{kDa}$ band is the dominant form of apPKG, because it is most abundant and has a greater affinity for CGMP than the $80 \mathrm{kDa}$ constituent (data not shown). Both bands were also recognized by a commercial antibody that was generated against human type-I $\alpha$ PKG (amino acid residues 657671: 50\% identity to apPKG) (data not shown). apPKG contains consensus sequences for several kinases and other enzymes and the $100 \mathrm{kDa}$ constituent might contain one or more posttranslational modifications. 


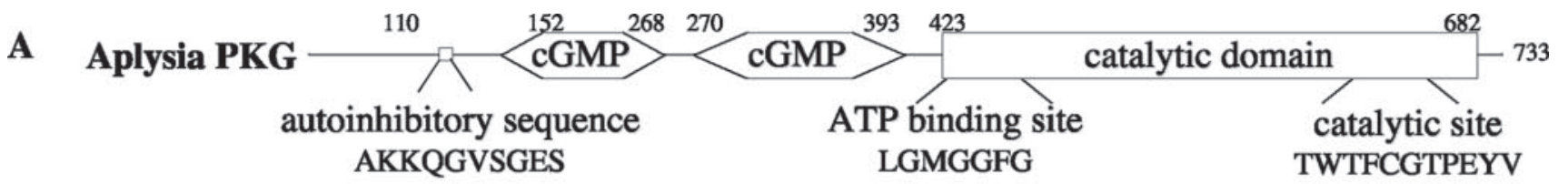

\begin{abstract}
aPPKG
DG1

hPKGIa

MPKGI

DG2T3A

MPKGII 1
1 MAAGMLTDREREA IVSNLTKDVQALREMVRSRESELVKLHRE I HKLKSVLQQTTNNLNVTRNEKAKKRLYSLPEQCGEQESRNQNPHLCSSCGMV . 作 年 1
1
\end{abstract}

apPKG

DG1

hPKGIa

MPKGIb

DG2T3A

DPKGI

MPKGII

a P PKG

DG 1

hPKG1 a

MPKG1b

DG2 T $3 \mathrm{~A}$

hPKGII

MPKGI I

apPKG

DG1

hPKG1a

DG2 T3A

hPKGII

MPKGI

apPKG

DG1

hPKGIa

MPKGIb

hPKGII

MPKGII

a P P K

DG1

hPKG1a

MPKGIb

DG2T3A

MPKGII

apPKG

DG1

hPKG1 a

MPKGIb

hPKGII

MPKGI I

a P PKG

DG

hPKGIa

MPKG1b

DPKGII

MPKGII

a P PKG

DGI

hPKG1a

MPKG1b

hPKGII

MPKGII

B

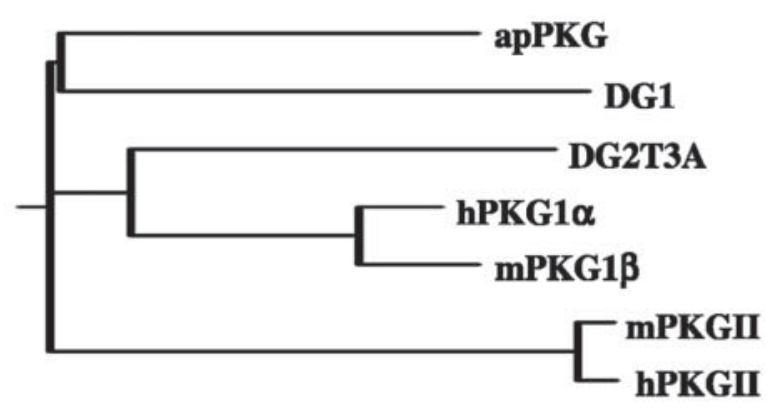

720 FDWDGLASQLLIP PFVRPIAHPTDVRYFDRFPCDLN - EPPDEL

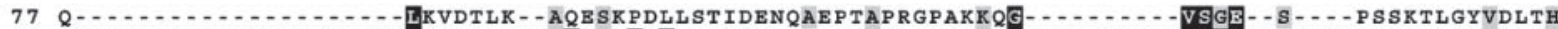
96 LPTSP 作

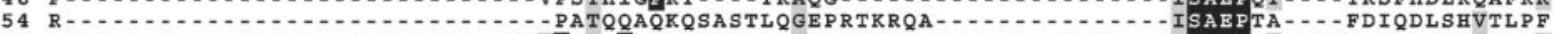

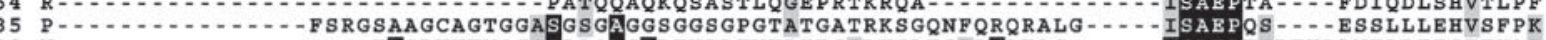
( 0 N

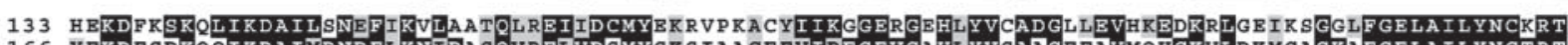

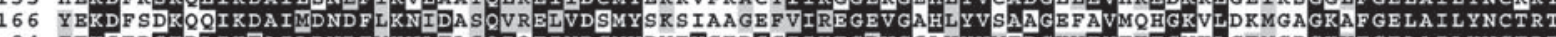
84 FTKSERSRDLIREAILDNDFMKNLELSQIREIVDCMYPVEYGKDSCIIKEGDVGS LVYVMEDGKVEVTKEGVRLCTMGPGKVFGELAILYNCTRT

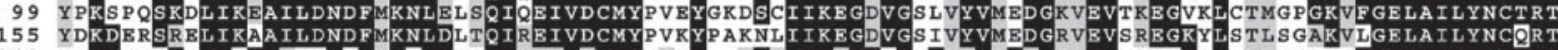
149 VRKDSSERKLITDALNKNQFLKRLDPQO IKDMVECMYGRNYQQGSYI I RGGEPGNHIFVLAEGRLEVFQGEKLISSIPMWTTFGELAILYNCTRT 228 ASVKAVTHTT-LWVLDRRVF QATMMKTGLQRR BENMAFLKSVPLLKNLPSDKLAKM SDVLEYDFFH ENEY I IREGAAGDTFF ILNKGEVKVTQKI 261 ASIRVLSBAARVWVLDRRVF Q IMMCT GLQRIENSVNFLRSVPLLMNLSEELLAKIADVLELEFYAAGTY I IRQGTAGDSFFLISDGNVRVTQRL 179 ATVKTLVNVR-LWATDRQCFOTIMMRTGLIKHTEYMEPLKSVPTFQSLPEE ILSKLADVLEETHYENGEYI IRQGARGDTFFIISKGTVIVTRED

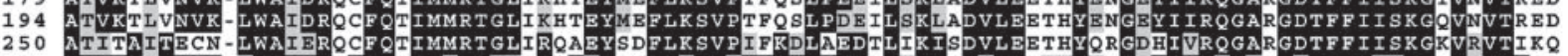
244 A SVKAITNVR-TWALDREVF QNIMRRTAQARDEQYRNFLRSVSLLKNLPEDKLTKIIDCLEVEYYDKGDYIIREGEEGSTFFILAKGKVIVTTQST

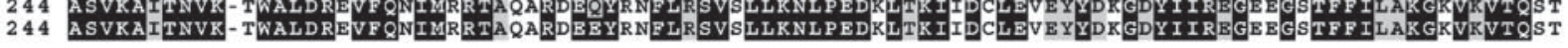

322 AGHA - ERKEVRRIKRGDYFGEKALLSEDRRTANVIAL P P - GVECLTVDRESFTQFVGDLNELR - - . - . - NRDYGDEARGAERR SG - - - - - SD 356 TPTSPBETELRTLSRGDYFGEQAL INEDKRTANI IALSP - GVECLTLDRDSFKRLIGDLCELK - - . - - BKDYGDESRKLAMKQA - - - - RE

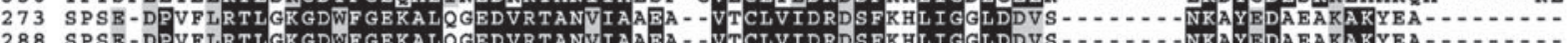

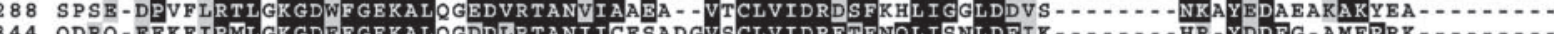

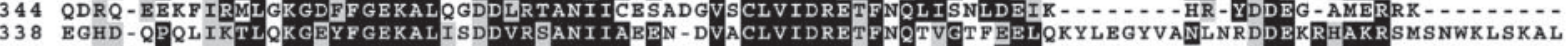

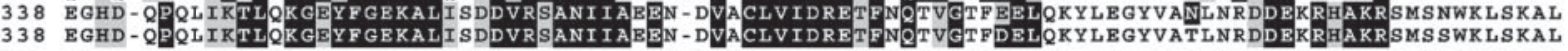

401 STV SPVSER PVAKEFENCS LDDLQLVTTLGMGGFGRVELVQLS - K BKGKT FALKCLKRKHIVETRQQEH IY SERK IMMEAD SPF ITKLHKTFRDR 436 SCQDEPKEQ-LQQEFPDLKLTDLEVVSTLGIGGFGRVELVKAHHQDRVDIFALKCLKKR

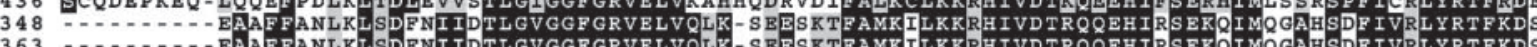
419
4

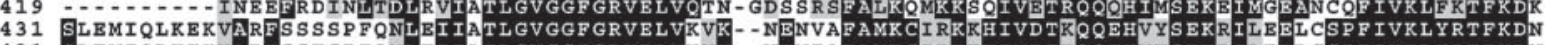
431 SLEMIQLKEKVARESSTSPFQNLEIIATLGVGGFGRVELVIKVK- -NENIAEAMKCIRKKHIVDTKQQEHVYSERRILEELCSPFIVKLYRTFKDN

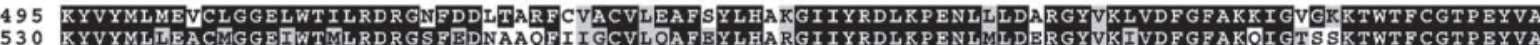

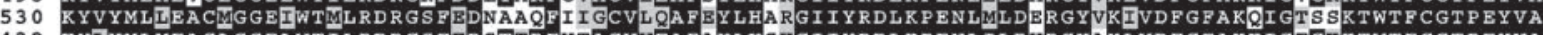

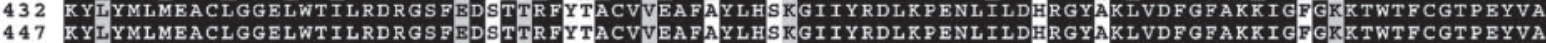
447 KYLYMLMEACLGGELWTILRDRGSFEDSTTRFYTACVVEAFAYLHSKGI IYRDLRPENLILDHRGYAKLVDFGFAKRIGFGKRTWTFCGTPEYVA
503 KYLYMLMESCLGGELWTILRDKGNFDDSTTRFYTACVVEAFDYLHSRNI IYRDLRPENLLLNERGYGKLVDFGFAKRLQTGRKTWTFCGTPEYVA 524 KYVYMLIEACLGGELWSI LRDRGSPDEPTSKFFVACVTEAFDY LHRLGI I R DLRPENLILDAEGYLKLVDFGFAKK IGSGRKTWTFCGTPEYVA

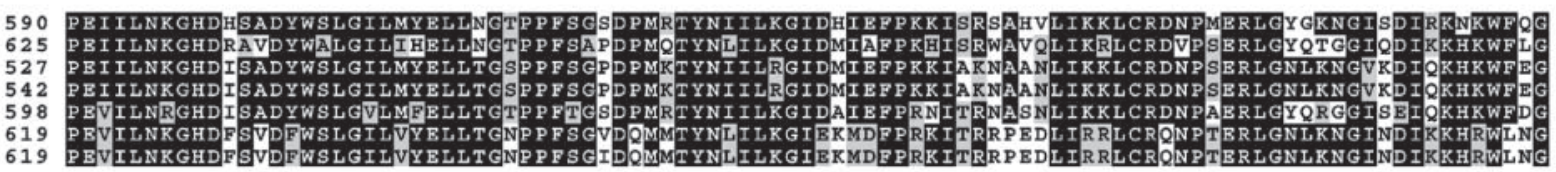

685 FDWDGLMDLTLTPPIVPKVKNPTDTSNFDSYPRDMD-IAADELSGWDIDF

622 FNWEGLRRGTLTPPIIPSVASPTDTSNFDSFPEDNDEPPPDDNSGWDID

637
PNWEGLRKGTLTPPIIPSVASPTDTSNPDSPPEDSDEPPPDDNSGWDID

714 FNWEGLKARSLPSPLQRELKGPIDHSYFDKYPPEKG - MP PDELSGWDKD
71

C

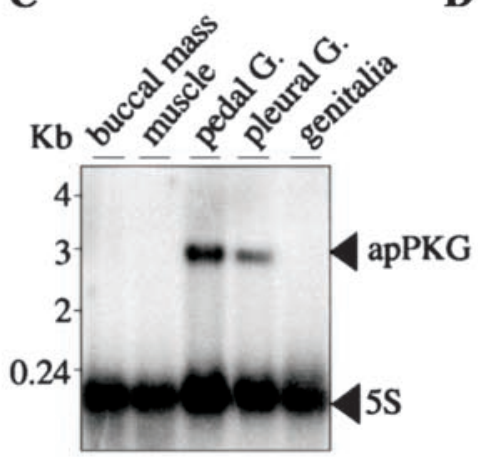

D

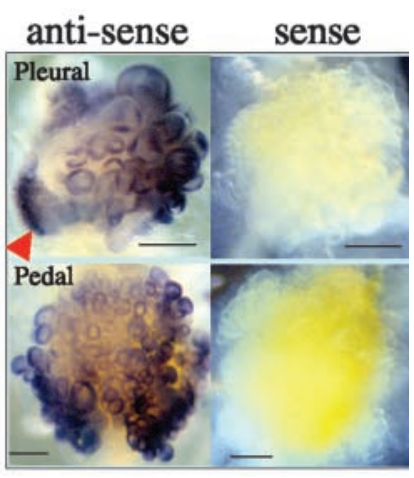


$\mathbf{A}$

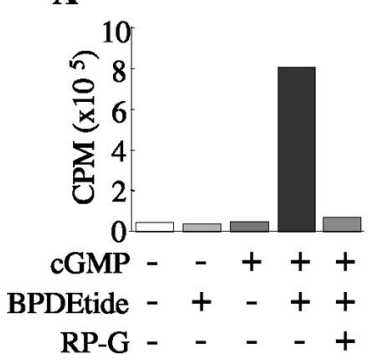

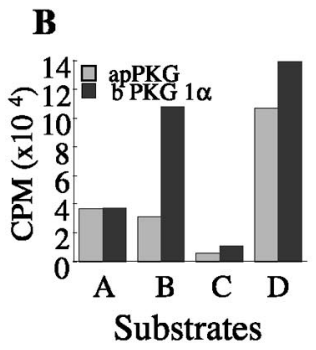

C

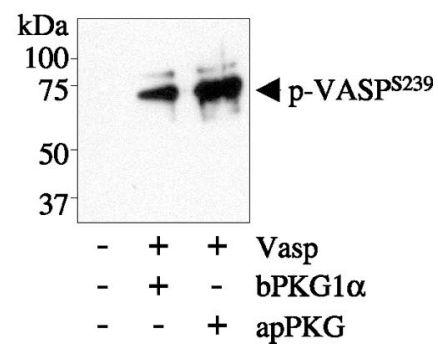

Figure 2. apPKG is a type-I PKG. A, The kinase activity of purified inactive recombinant apPKG protein (100 $\mathrm{ng})$ was measured by the transfer of ${ }^{32} \mathrm{P}$ from [ $\left.{ }^{32} \mathrm{P}\right] \mathrm{ATP}$ to BPDEtide in the presence $(+)$ or absence $(-)$ of $100 \mathrm{~nm} 8$-Br-cGMP. Activity caused by autophosphorylation was subtracted using a peptide control reaction (see Materials and Methods). Note that the kinase activity was inhibited in the presence of $10 \mu \mathrm{M}$ PKG inhibitor Rp-8-pCPT-cGMPS (RP-G). B, Kinase activity of active recombinant apPKG (25 $\mathrm{ng}$ ) and bovine PKG type-l $\alpha$ (bPKG1 $\alpha$ ) (50 ng) in the presence of four type-I PKG peptide substrates: peptide A, RKISASGP; $B$, RKISASEFDRPLR (BPDEtide); and D, RKRSRAE (H2Btide). Peptide C, QKRPRRKDTP, is a type-II PKG substrate. C, apPKG phosphorylates recombinant VASP at serine-239. Purified recombinant VASP-GST $(0.5 \mu \mathrm{g})$ was incubated with active aPPKG $(100 \mathrm{ng})$ or the recombinant bovine PKG $(50 \mathrm{ng})$, or in the kinase buffer alone, at room temperature for $20 \mathrm{~min}$. After SDS-PAGE, a Western blot was probed with an anti-phospho-VASP $\left(\operatorname{Ser}^{239}\right)\left(p^{-V A S P}{ }^{5239}\right)$ antibody.

To determine whether apPKG is present in axons, we extruded axoplasm from nerves $\mathrm{p} 5-\mathrm{p} 9$. Figure $3 A$ shows that both polypeptides were present. The SNs have axons in nerves $\mathrm{p} 5-\mathrm{p} 9$, and immunocytochemistry with $\mathrm{Ab}^{\text {apPKG}}$ stained essentially all of the SNs in the cluster (Fig. 3B).

To determine the effects of nerve injury on axonal apPKG, we crushed nerves $\mathrm{p} 5-\mathrm{p} 9$ on one side, thereby axotomizing the axons in each nerve. At various times afterward, we assayed apPKG activity in the ipsilateral and contralateral pedal and pleural ganglia, which included the cluster of SN cell bodies. As shown in Figure $4 A$, there was a delay of $\sim 16 \mathrm{hr}$ after nerve crush before significant apPKG activity appeared in the ipsilateral pleural ganglion. The activity then increased for at least $24 \mathrm{hr}$, but was not significantly different from baseline at $48 \mathrm{hr}$. Little or no apPKG activity was detected in the contralateral control pleural ganglion (Fig. 4A). Significantly, apPKG activity in the cell bodies of the ipsilateral pedal ganglion neurons remained at basal level during the $48 \mathrm{hr}$ after axotomy (Fig. $4 \mathrm{~A}$ ), indicating that the activation of apPKG is selective for neurons in the pleural ganglion.

The long delay before apPKG activity appeared in the cell bodies is consistent with the idea that the kinase is a positive injury signal. Moreover, apPKG contains a nuclear localization sequence (NLS) that can provide access to the retrograde transport system (Ambron and Walters, 1996; Schmied and Ambron, 1997; Hanz et al., 2003). To investigate this possibility, we used a standard crush-ligation protocol (Ambron et al., 1995; Johanson et al., 1995) (Fig. 4B). Nerves p5-p9 were crushed unilaterally, and a ligation was placed on each nerve proximal to the crush site. Proteins that are transported away from the crush site (toward the cell bodies) accumulate in the axoplasm behind the ligation where they can be collected. $24 \mathrm{hr}$ later we removed $0.5 \mathrm{~cm}$ nerve segments: (1) proximal to the crush $(\mathrm{Cr})$ site, (2) distal to the ligation on the crushed nerves (the $\mathrm{Cr} / \mathrm{Lig}$ site), and (3) distal to

the ligation on the control side (the Lig site) (Fig. $4 B$, top). Axoplasm was then extruded from each segment, as well as from segments of nerves p5-p9 from an animal that did not receive a nerve injury.

When equal amounts of each axoplasm were screened for apPKG activity, there was a 10 -fold increase in apPKG activity in axoplasm from the $\mathrm{Cr} / \mathrm{Lig}$ segment relative to basal activity in axoplasm from noninjured animals (Fig. $4 B$, bottom). In contrast, apPKG activity at the $\mathrm{Cr}$ segment was only threefold greater than the basal activity, and that at the Lig segment was at the basal level.

The accumulation of apPKG activity at the $\mathrm{Cr} / \mathrm{Lig}$ site was supported by immunocytochemical studies in which we used $\mathrm{Ab}^{\text {apPKG}}$ to examine the distribution of apPKG protein in noninjured and injured nerves. apPKG staining was uniformly distributed along axons in naive nerves (Fig. 4C, panel 1). After nerve crush, however, there was a decrease in the staining at the Cr site (Fig. 4C, panel 3) and a significant increase at the terminations of axons at the $\mathrm{Cr} / \mathrm{Lig}$ site (panel 4). There was no increase in staining at the Lig site (Fig. 4C, panel 2). The accumulation of both apPKG protein and activity at the $\mathrm{Cr} / \mathrm{Lig}$ site relative to the $\mathrm{Cr}$ and Lig sites is strong evidence that apPKG is a positive injury signal (Ambron et al., 1995).

\section{The nitric oxide-cGMP-PKG pathway regulates the induction of LTH in SNs in vitro}

When Aplysia SNs are axotomized by removal from the ganglion and individually placed in culture, they regenerate their axons and exhibit a decrease in spike threshold and an increase in repetitive firing, which are two characteristics of LTH (Ambron et al., 1996; Bedi et al., 1998; Sung and Ambron, 2004). To examine the appearance of this LTH in greater detail, we recorded from the SNs in vitro on the second to the seventh day and compared their electrical properties with those from SNs within the cluster in situ. Approximately $10 \%$ of the cells tested in vitro did not have a sufficient resting potential or were refractory to firing and were not included in the study. We detected the same decrease in threshold and increase in repetitive firing as reported previously, and also found that the axotomized SNs exhibited significant spike broadening and an increase in spike amplitude relative to the controls (Fig. 5). The changes were significant on the second day and persisted until at least the seventh day. The fact that these same four changes in electrical properties occur in hyperexcitable rat DRG SNs after axotomy (Abdulla and Smith, 2001), affirms the use of dissociated Aplysia SNs as a model system for studies of sensory alterations that may contribute to neuropathic pain.

To investigate whether the appearance of the LTH requires apPKG activity, we removed the SNs from the ganglion in the

Figure 1. A, Top, A schematic diagram of apPKG showing the position of the conserved tandem cGMP binding domains, the ATP binding and catalytic sites, and the position of an autoinhibitory sequence. Bottom, Clustal W sequence alignment of the predicted apPKG amino acid sequence with Drosophila DG1 (GenBank accession number AAB03405) and DG2T3a (AAA28459), human I $\alpha$ (BAA08297) and II (CAA64318), mouse I $\beta$ (AAD16044) and II (AAA02572), and rat II (CAA85284) PKGs. Conserved amino acids are shaded in black; similar amino acids are shaded in light gray. B, Phylogenetic analysis of the PKG family. C, Expression of apPKG in neurons. A multiple-tissue Northern blot was hybridized with a 32 P-labeled N-terminal apPKG CDNA fragment. The arrow indicates apPKG mRNA. The sizes of RNA standards are indicated to the left of the figure. A $^{32} \mathrm{P}$-labeled probe to 55 ribosomal RNA (arrow) was used to ensure loading uniformity. D, apPKG mRNA localization in pleural and pedal ganglia by in situ hybridization with a digoxigenin-labeled antisense RNA (left) or sense-RNA (right). apPKG mRNA is expressed in the pleural sensory cluster (arrow). Scale bar, $200 \mu \mathrm{m}$. 
$\mathbf{A}$

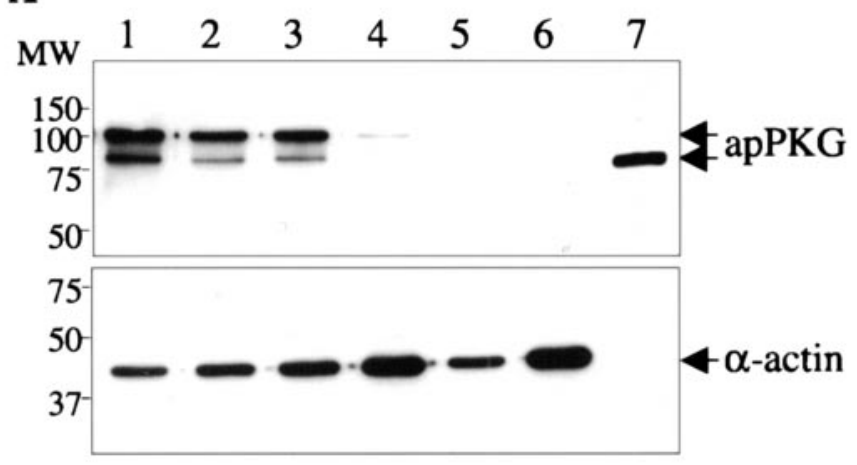

B

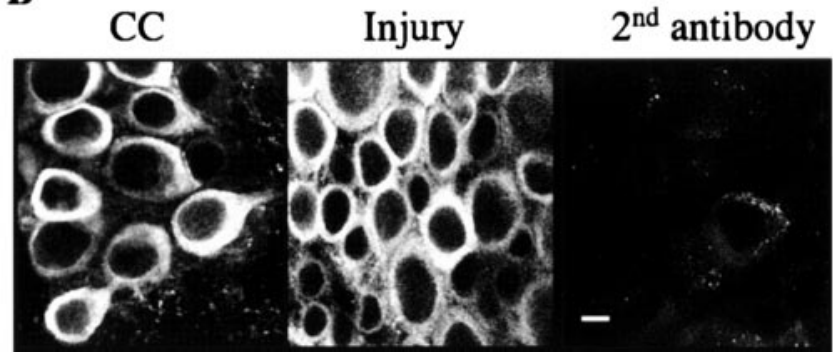

Figure 3. A, apPKG protein expression in the nervous system. Top, A Western blot (10 $\mu \mathrm{g}$ of protein per lane) was probed with antibody $\mathrm{Ab}^{\mathrm{aPPKG}}$ raised against an $\mathrm{N}$-terminal peptide of apPKG protein. Lane 1, Pedal ganglia; lane 2, pleural ganglia; lane 3, axoplasm extruded from peripheral nerves; lane 4, body wall muscle; lane 5, buccal mass; lane 6, genitalia; lane 7, recombinant apPKG. The two specific apPKG signals are indicated by arrows. Bottom, The blot was stripped and reprobed with an antibody against $\alpha$-actin to indicate protein load. Positions of molecular mass markers in kilodaltons are indicated on the left. $B$, apPKG is expressed in the Aplysia SNs. Confocal microscopy of a $2 \mu \mathrm{m}$ optical section taken from a Z-series through the pleural sensory cluster exposed to $\mathrm{Ab}{ }^{\text {apPKG }} 24 \mathrm{hr}$ after nerve crush in vivo. Shown are representative images of contralateral uninjured $(C C)$ and injured sensory clusters from sections in the middle of the neuron to show the nucleus. An injured sensory cluster stained in the presence of second Ab only shows the background staining. Scale bar, $20 \mu \mathrm{m}$. Although the staining is primarily in cytoplasm, the nucleus of some neurons is also stained. Note that the apPKGstaining pattern is essentially identical between injured and contralateral uninjured sensory clusters.

presence of either the soluble guanylyl cyclase (sGC) inhibitor ODQ, the PKG inhibitor Rp-8-pCPT-cGMPS, or the PKA inhibitor Rp-cAMPS. We used the latter because PKA has properties in common with PKG (Scott, 1991; Francis and Corbin, 1994) and has been implicated in various forms of synaptic plasticity in Aplysia SNs (Ghirardi et al., 1992; Byrne and Kandel, 1996; Bedi et al., 1998; Muller and Carew, 1998; Chain et al., 1999; Liao et al., 1999; Sutton and Carew, 2000; Antonov et al., 2003). The cells were subsequently allowed to regenerate in the presence of the inhibitors in vitro, and on the third day, their electrophysiological properties were compared with those of SNs that were removed from the same ganglia at the same time, but that had not been exposed to a drug. We found that both Rp-8-pCPT-cGMPS and ODQ prevented the increase in repetitive firing (Fig. $6 A$ ) and the decrease in spike threshold $(B)$. In contrast, the PKA inhibitor had no significant effect on either parameter. Neither Rp-8pCPT-cGMPS nor ODQ inhibited the appearance of excitability when added to 2-d-cultured SN (data not shown), confirming the data in Figure $4 \mathrm{~A}$ showing that apPKG activation is transient. We did not examine spike broadening or amplitude in these experiments. None of these treatments, which used similar or even lower concentrations of the drugs than that reported for mam- malian (Monfort et al., 2002) and Aplysia neurons (Lewin and Walters, 1999), affected the resting membrane potential. Significantly, they also did not alter the extent or pattern of neurite growth. In contrast, exposing SNs to U0126, a selective MEK inhibitor, produced severe growth defects (data not shown). We did not examine these cells further.

The inhibition of LTH by the sGC and PKG inhibitors indicated that cGMP synthesis and PKG activation occur within the sensory neurons. NO is known to elevate cGMP production via sGC (Schlossmann et al., 2003), and NO is produced by the enzyme NOS (Bredt and Snyder, 1990; Moroz et al., 1996). To investigate the likelihood that NOS activation is required for LTH, we first used RT-PCR to detect the cellular levels of apnNOS mRNA in single SNs immediately after their removal from the ganglion $(0 \mathrm{hr})$ or after $16 \mathrm{hr}$ in vitro. As shown in Figure $6 \mathrm{C}$ (top panel), four of five cells expressed significant amounts of apnNOS mRNA after $16 \mathrm{hr}$ in vitro, whereas none was detected in the $0 \mathrm{hr}$ cells. In contrast, the mRNA for the SN-specific neuropeptide sensorin A (Brunet et al., 1991) and the neuronspecific isoform of actin (DesGroseillers et al., 1994) was abundant in every cell (Fig. 6C, second and third panels, respectively).

L-Thiocitrulline is an effective inhibitor of apNOS, and we found that exposing the SNs to this drug in vitro as above markedly reduced the maximum firing relative to untreated controls (Fig. $6 D$ ). Another NOS inhibitor, L-NAME also reduced LTH under the same conditions, but was not as effective as L-thiocitrulline (Fig. $6 D$ ).

These data indicate that the NO-cGMP-PKG pathway is required for inducing LTH in the SNs.

\section{Somatic apMAPK is phosphorylated at its activation site by apPKG}

The induction of LTH in Aplysia SNs after peripheral injury requires gene transcription (Lewin and Walters, 1999) and could be effected directly by apPKG if the kinase translocated to the nucleus after entering the cell body. Immunostaining revealed a low constitutive level of apPKG in some SN nuclei, but there was no increase after axotomy (Fig. 3B). This suggested that apPKG contributes to the induction of LTH by activating a factor that is imported into the nucleus. An ERK member of the MAPK family is a good candidate for this factor, because LTH can be induced by injecting recombinant ERK1 into SN somata (Sung et al., 2001). To assess whether an ERK was activated after injury, we crushed p5-p9 in vivo and subsequently probed Western blots of injured and control pleural neurons with an antibody $\left(\mathrm{Ab}^{\mathrm{p}^{\text {TpYmapk }}}\right)$ that recognizes ERKs that have been activated by dual phosphorylation at the T-E-Y site. The antibody recognized a single $43 \mathrm{kDa}$ polypeptide that had little activity in pleural neurons $4 \mathrm{or} 8 \mathrm{hr}$ after the injury (Fig. $7 A$, top panel). By $16 \mathrm{hr}$, however, there was more active kinase on the crush side relative to the contralateral control, and the level continued to increase for at least $48 \mathrm{hr}$ (Fig. $7 A$, top panel).

Aplysia neurons contain an ERK2 homolog, apMAPK (Michael et al., 1998), that enters the nucleus after injury in vitro (Martin et al., 1997). apMAPK has the same catalytic domain and T-E-Y activation site as ERKs 1 and 2. To determine whether apMAPK was the kinase activated after injury, we probed the same blot with an antibody, D8, which specifically recognizes apMAPK (Martin et al., 1997), and found that the antibody recognized the $43 \mathrm{kDa}$ injury-activated kinase (Fig. 7A, bottom panel). The antibody detects both active and inactive apMAPK, and there was little difference in the amount of total apMAPK protein among the samples.

The finding that apMAPK activity began to increase just after 
$\mathbf{A}$
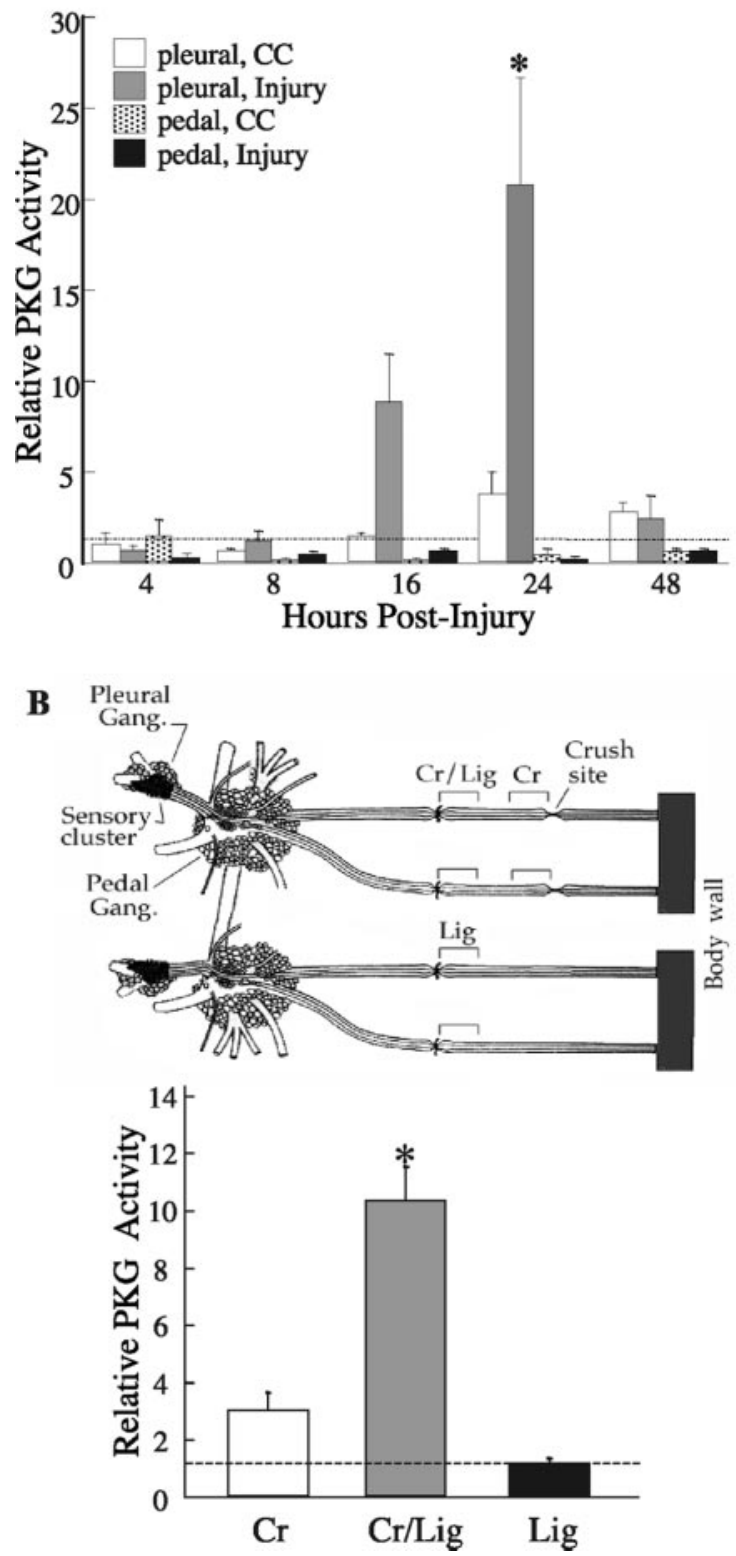

Figure 4. ApPKG activity appears in the pleural ganglion after a delay after nerve crush. $A$, Peripheral nerves $p 5-p 9$ were crushed on one side. At the indicated times, pleural (white/gray squares) and pedal (dotted/black squares) ganglia were collected from the injured (black/gray) and contralateral control (CC) (white/dotted) sides and assayed for apPKG activity using BPDEtide as substrate in the presence of the PKA-specific inhibitor 6-22 amide. ApPKG activity at each point was corrected for autophosphorylation and was normalized to total apPKG activity elicited by adding $1 \mu \mathrm{m} 8$-Br-cGMP to a duplicate sample. Relative apPKG activity was the ratio of the apPKG activity of each sample to the basal apPKG activity in a sample from a naive animal. Six animals were examined independently at each time point. Two-way ANOVA with repeated measures showed significant effects of axotomy, time, and their interaction in the pleural ganglia ( $p<0.001$ in each case). $B$, apPKG is activated and retrogradely transported after injury. p5-p9 nerves were crushed and ligated. Twenty-four hours later, axoplasm was extruded from the crush ( $\mathrm{Cr}$ ) site, from the crush/ligation ( $\mathrm{Cr} / \mathrm{Lig}$ ) site, and from the ligation (Lig site) on the control nerves, as indicated by brackets in the schematic. Axoplasm containing equal amounts of protein from each segment was assayed for apPKG activity as in $A$. The line indicates the level of basal apPKG activity, determined by assaying axoplasm collected from noninjured nerves. Error bars represent \pm SEM. An asterisk indicates significant difference compared with all of the other groups ( $p<0.05$; ANOVA and NewmanKeuls tests). An enrichment of active apPKG at the $\mathrm{Cr} /$ Lig site is characteristic of positive molecular injury signals. C, ApPKG protein is retrogradely transported after injury. Peripheral nerves were crushed and ligated as in $B$. Twenty-four hours later, injured and control nerves were fixed, exposed to $A b^{\text {apPKG }}$, and processed for immunohistochemistry. Optical sections ( $\left.2 \mu \mathrm{m}\right)$ through each nerve were examined by confocal microscopy. All of the images were at the same magnification and were captured after identical exposures to the confocal beam. Each image is aligned in the same direction; the central somata are to the left of the segment shown. 1, Segment of a nerve from a noninjured animal. 2, Segment containing the Lig site (arrow) on a nerve contralateral to the injury. 3, Segment of nerve containing the $\mathrm{Cr}$ site (arrow), which has expanded over the $24 \mathrm{hr}$. 4, Segment of nerve containing the $\mathrm{Cr} / \mathrm{Lig}$ site (arrow). 5, Segment of nerve exposed to the second antibody only. Scale bar, $20 \mu \mathrm{m}$ for all of the images. the arrival of active apPKG in the cell body (compare Figs. 4A, 7A) suggested a link between apPKG and apMAPK. We tested this idea by preparing a lysate of pleural ganglion neurons and using $\mathrm{Ab}^{\mathrm{pTp}^{\mathrm{T} Y \mathrm{Ymak}}}$ to monitor samples for active apMAPK. Little endogenous phospho-apMAPK was detected in the lysate (Fig. $7 B$, lane 1), but adding active apPKG or 8-Br-cGMP markedly enhanced the level of active apMAPK (lanes 2, 3) that was recognized by antibody D8 (data not shown). Surprisingly, the activation was not blocked by U0126, a potent inhibitor of the upstream kinase MEK (Fig. 7B, lane 4). Interestingly, adding active apPKG to axoplasm did not activate apMAPK (Fig. 7B, lanes 5,6) (see Discussion). Another study with the lysate showed that the apPKG-activated apMAPK phosphorylated its physiological substrate, Elk1, at the appropriate Ser $^{383}$ (Fig. 7C, lane 3).

The activation of apMAPK in the presence of U0126 suggested that apPKG activates apMAPK directly, and we therefore incubated active apPKG with recombinant mammalian ERK2. ERK2 was a surrogate for apMAPK, because we do not have recombinant apMAPK. Both kinases contain the target T-E-Y site, however. As in the lysate, apPKG activated ERK2 to phosphorylate Elk1 (Fig. 7C, lane 6). When the experiment was repeated, the activated ERK2 was recognized by $\mathrm{Ab}^{\text {PTpYMAPK }}$, indicating that it was doubly phosphorylated (Fig. 7D, top, lane 2). The activation was specific, because it was reduced in the presence of BPDEtide (Fig. 7D, top, lane 3). ERK2 is maximally activated when both the - T- and -Y- amino acids are phosphorylated, yet PKGs are serine/threonine kinases. It is relevant, therefore, that bacterial recombinant ERK2 has a low level of activity that is attributable to the presence of a phosphate on the -Y- moiety (Cha and Shapiro, 2001). Indeed, the antibody to ERK $^{\text {pY185 }}$ recognized the recombinant ERK2 substrate on a Western blot (Fig. 7D, middle). There was no increase in phosphorylation of the -Y- when ERK2 was incubated with apPKG (Fig. 7D, middle, lane 2). However, when a duplicate blot was probed with an antibody to $\mathrm{ERK}^{\mathrm{pT} 183}$, there was an increase in the phosphorylation of the -T- in the presence of apPKG (Fig. 7D, bottom, lane 2). This antibody reacts specifically with the monophosphorylated threonine and doubly phosphorylated ERKs. Our result indicates that apPKG can fully activate ERK2 by phosphorylating ERK2 that already contains a phosphate on the $-\mathrm{Y}$-.

We next examined whether incubating 
$\mathbf{A}$

Day 0

Day 7
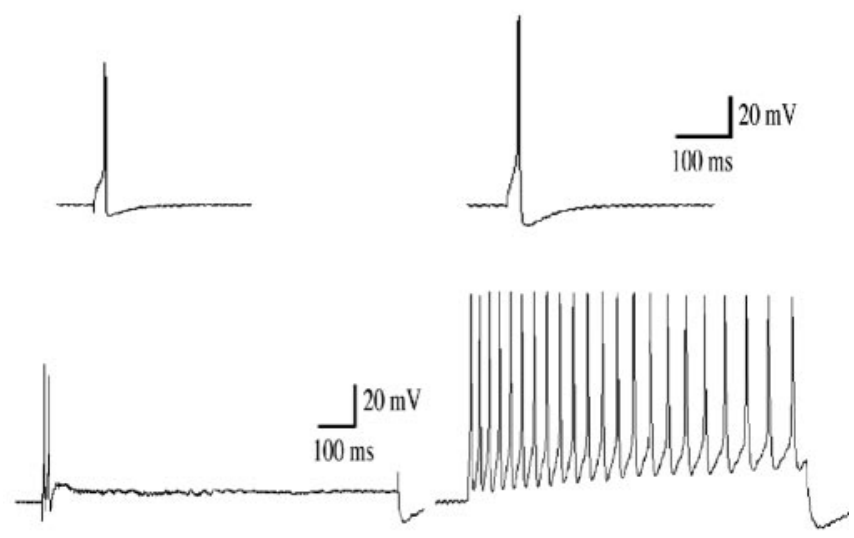

B
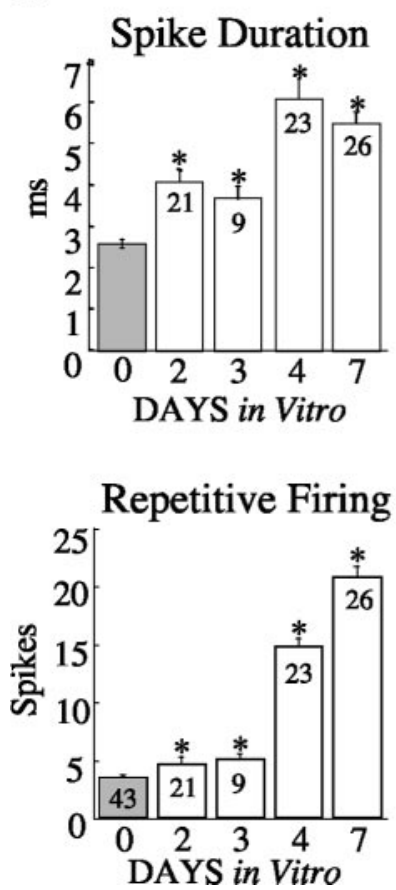
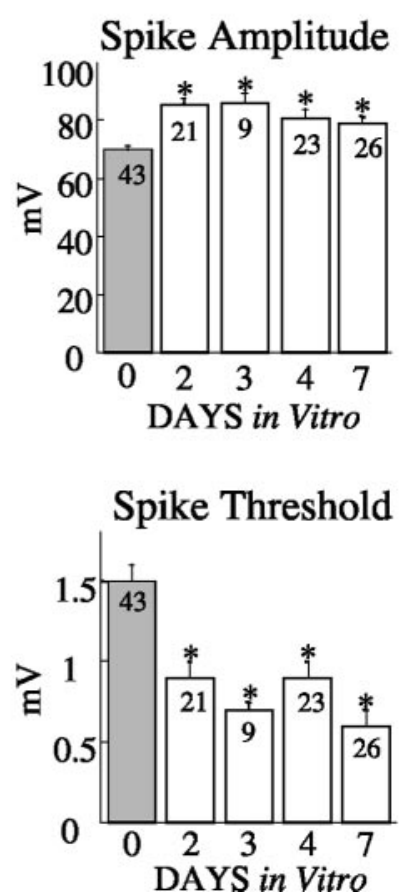

Figure 5. SNs develop an LTH in vitro. The electrical properties of SNs after time in vitro were compared with those in control SNs in the sensory cluster in vivo ( $\mathrm{d} 0$ ). A, Top, A representative single action potential elicited in response to a $20 \mathrm{msec}$ depolarizing pulse showing the increase in spike amplitude after $7 \mathrm{~d}$ in vitro. Bottom, Action potential discharge in response to a normalized 1 sec intracellular test pulse. Note the repetitive firing in the neurons after $7 \mathrm{~d}$ in vitro. $B$, Data comparing spike duration, spike amplitude, spike threshold, and repetitive firing of control SNs (gray bars) with those after 2-7 din vitro (open bars). Each bar contains the number of cells examined. Error bars represent \pm SEM. An asterisk indicates significant difference from the in vivo value ( $p<0.01$; ANOVA and Newman-Keuls test).

apPKG and recombinant ERK2 produces an active ERK2 with enzymatic activity comparable with that produced by MEK1, which produces the maximally activated kinase. ERK2 activity was measured by the phosphorylation of Elk1 at Ser ${ }^{383}$, and MEK1 was activated by the catalytic subunit of MEKK1 (Xu et al., 1995). As we anticipated, apPKG produced an ERK2 with similar activity as that produced by MEK1 (Fig. 7E). This result indicates that, in addition to MEK1, PKG is an activator of ERK2.
Because PKG phosphorylates T183 on ERK2 that already has a phosphate on Y185 (Fig. 7D), an essential question is whether monophosphorylated apMAPK at -Y- is available for phosphorylation by apPKG after axotomy. We answered this question by first crushing p5-p9 in vivo. Samples were then blotted and probed with an antibody to $\mathrm{ERK}^{\mathrm{pY} 185}$. Indeed, apMAPK ${ }^{\mathrm{pY}}$ was present in pleural neurons $8 \mathrm{hr}$ after the injury, and its expression was increased on the crush side relative to the contralateral control at $16 \mathrm{hr}$ (Fig. $7 F$, top panel). ApMAPK ${ }^{\mathrm{pY}}$ was not detected in two naive animals that were analyzed (Fig. $7 F$, top panel). Probing the blot with an antibody that detects both active and inactive apMAPK showed that there was little difference in the amount of total apMAPK protein among the samples (Fig. 7F, bottom panel). Thus, the presence of apMAPK ${ }^{\mathrm{pY}}$ in the soma $16 \mathrm{hr}$ after the injury, in conjunction with the arrival of apPKG from the crush site (Fig. $4 A$ ), should result in full activation of apMAPK.

The level of apMAPK in the nucleus of SNs in vitro is reduced when apPKG activity is inhibited

We have evidence above that apPKG does not enter the nucleus of the $\mathrm{SNs}$ in response to nerve crush in vivo (Fig. $3 B$ ). Nevertheless, type-I PKGs have a putative NLS (Gudi et al., 1997), and apPKG has a short stretch of positively charged amino acids $\left({ }^{453} \mathrm{KCLKKKHI}\right)$ in the ATP-binding domain that could function as an NLS. The import of proteins into the nucleus of Aplysia neurons is readily assessed by injecting their fluorescently labeled cognates directly into the cell body (Ambron et al., 1992; Schmied et al., 1993; Gunstream et al., 1995). We therefore injected Alexalabeled recombinant apPKG into the soma of SNs after $2 \mathrm{~d}$ in vitro, severed the neurites to initiate an injury response, and, 30 min later, examined the cells by fluorescence microscopy. All of the labeled protein remained in the cytoplasm (Fig. 8A). Alexalabeled BSA also remained in the cytoplasm after injection, as expected (Ambron et al., 1992; Schmied et al., 1993; Gunstream et al., 1995). In contrast, injected Alexa-labeled active recombinant vertebrate ERK1, which is imported into the nucleus in a variety of cell types (Karin, 1994) rapidly entered the nucleus where it was distributed in discrete patches (Fig. 8A). Similar patches have been seen after the import of other proteins into Aplysia nuclei (Ambron et al., 1992; Schmied et al., 1993; Gunstream et al., 1995).

The inability of apPKG to enter the nucleus of Aplysia SNs is consistent with the idea that it contributes to the induction of LTH by promoting the nuclear import of apMAPK. If so, then inhibiting the apPKG pathway should block the axotomyinduced entry of apMAPK into the nucleus. We therefore exposed SNs in vitro either to the PKG blocker, Rp-8-pCPTcGMPS, or the PKA blocker, Rp-cAMPS, under the conditions that induce LTH (Fig. 6A). On the third day, the cells were fixed, permeabilized, and exposed to antibody D8 to visualize apMAPK. Confocal microscopy showed that untreated cells and those exposed to Rp-cAMPS had the same levels of nuclear staining (Fig. 8 B). In contrast, there was a dramatic reduction in nuclear staining in the cells treated with Rp-8-pCPT-cGMPS (Fig. $8 \mathrm{~B})$. Thus, both the induction of LTH and the presence of apMAPK in the nucleus depend on apPKG activity.

\section{Discussion}

Persistent neuropathic pain in humans after nerve injury is physically and psychologically debilitating. Because an important component of this pain is often the LTH that appears in primary afferent neurons, it is important to understand how axotomy induces LTH. An LTH with similar properties appears in noci- 
$\mathbf{A}$

B
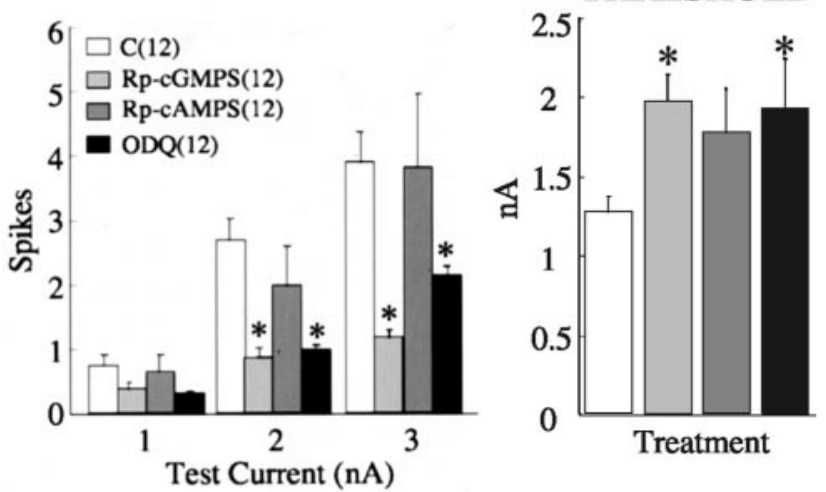

C

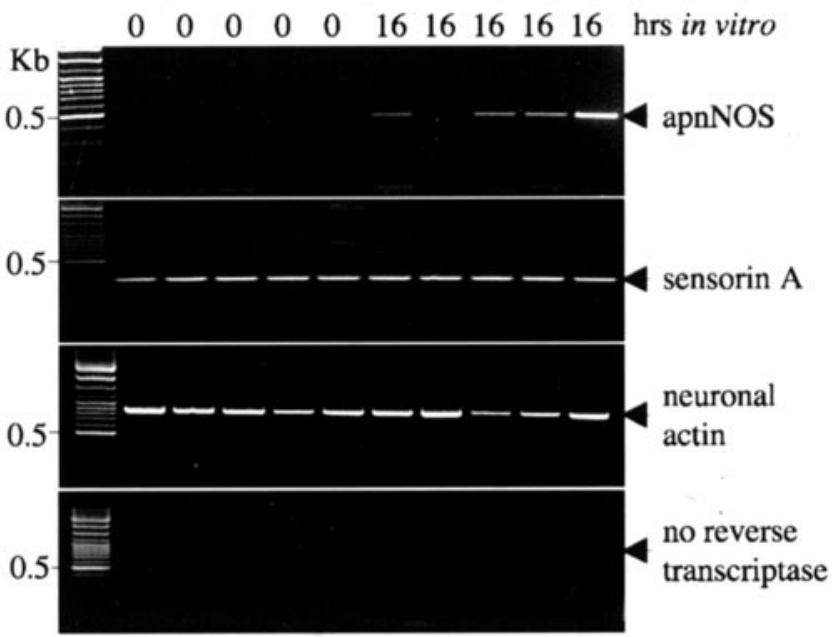

D

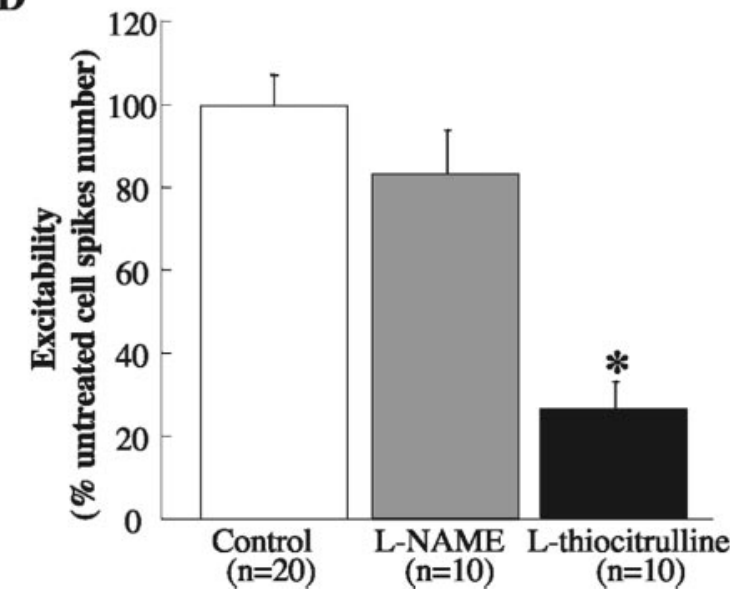

Figure 6. Inhibiting NOS, $S G C$, or apPKG prevents the induction of LTH in SNs in vitro. SNs were removed from the cluster and grown in vitro in the presence of Rp-8-pCPT-cGMPS (Rp(GMPS), Rp-CAMPS, or ODQ (all $10 \mu \mathrm{M}$ ). Other SNs removed at the same time were not exposed to any inhibitors as controls (C). $A, B, 0 \mathrm{n}$ the third day in vitro, 12 SNs exposed to Rp-cGMPS, Rp-CAMPS, or ODQ, and 12 control SNs were impaled with a microelectrode to assess repetitive firing in response to stimulation at three test currents $(A)$ and to determine spike threshold $(B)$. We examined the cells on the third day, and not later, to avoid more prolonged exposure to the drugs. Two-way ANOVA with repeated measures showed that both Rp-CGMPS and ODQ significantly reduced repetitive firing elicited by test currents of 2 and $3 \mathrm{nA}$ relative to controls. Error bars indicate SEM, and the asterisks indicate significance ( $p<0.0001$ in each case). Similarly, Rp-cGMPS and ODQ significantly prevented the injury-induced decrease in threshold compared ceptive SNs of Aplysia after axotomy, and we exploited the experimental advantages of these neurons to define a signaling pathway responsible for the induction of LTH. One major surprise was that this pathway involves the phosphorylation of apMAPK by PKG. This is an alternative to the traditional MAP kinase cascade and suggests that PKG and MAPK have unique roles after nerve injury.

\section{ApPKG is a positive injury signal in $\mathrm{SNs}$}

We cloned an Aplysia type-I PKG whose mRNA is in the SNs and other neurons in the pleural ganglion (Fig. 1D). When we crushed the peripheral nerves in vivo, apPKG activity appeared in the somata of pleural neurons, but only after a delay of $\sim 16 \mathrm{hr}$ (Fig. 4A). A similar delay in response to nerve injury has been attributed to positive injury signals (Schmied et al., 1993; Sung et al., 2001; Lin et al., 2003), and we knew from Western blots probed with $A b^{\text {apPKG }}$ that apPKG is present in axoplasm extruded from the peripheral nerves (Fig. $3 A$ ). In addition, because proteins are retrogradely transported along Aplysia axons at a rate of $1.5 \mathrm{~mm} / \mathrm{hr}$ (Ambron et al., 1992; Schmied et al., 1993; Gunstream et al., 1995), the delay is consistent with the transport of apPKG from the crush site, which was located $2 \mathrm{~cm}$ from the ganglion. We then placed a ligation proximal to the crush site and found that activated apPKG and total apPKG protein accumulated on the distal side of the ligation, relative to the crush site (Fig. $4 B, C$ ). These findings establish apPKG as a positive injury signal.

We do not know the mechanism responsible for the injuryinduced transport. Although apPKG contains several potential myristoylation sites that could bind it to vesicles after injury, we always found apPKG to be soluble after subcellular fractionation. Hanz et al. (2003) have shown that proteins containing an NLS are retrogradely transported via dynein and importins in the rat sciatic nerve, and we are presently investigating this interesting possibility. The latter gains importance, because we recently found that a type-I PKG is activated and transported retrogradely in the sciatic nerve (Y.-J. Sung and R. T. Ambron, unpublished observations).

\section{The appearance of the LTH in axotomized Aplysia SNs in} vitro depends on NOS, sGC, apPKG, and apMAPK

The LTH that appears in both the SNs (Fig. 5) and mammalian nociceptive SNs after nerve injury (Abdulla and Smith, 2001) have similar electrophysiological properties. If, as we believe, this congruence reflects conserved mechanisms, then LTH might be induced by common pathways in both types of cells. We examined SNs in vitro and found that the axotomy-induced reduction

with C cells (ANOVA and Fisher's PLSD tests; $p<0.05$ ). There was a considerable variability in threshold in the presence of the Rp-CAMPS, and the mean difference from controls was not significant. C, Detection of nNOS mRNA in single SNs by RT-PCR. Fragments of appropriate lengths were amplified with primer sets for apnNOS, sensorin A, and the neuron-specific isoform of actin from five separate sets of samples from SNs in vivo (0) or after $16 \mathrm{hr}$ in vitro. The size of the synthesized fragments detected by ethidium bromide staining on $2 \%$ agarose gels were identical with those predicted from the known sequences in the database. In addition, the PCR products were verified by DNA sequence analysis. Finally, there was no amplification in the absence of reverse transcriptase, indicating the RNA preparations were not contaminated by genomic DNA (bottom panel). Positions of molecular markers are indicated on the left. D, Effects of the NOS inhibitors on LTH. L-Thiocitrulline $(50 \mu \mathrm{M})$ and L-NAME $(1 \mathrm{mM})$ were used as described above. $n$, Number of $S \mathrm{~N} s$. The data were normalized to the average excitability of control cells in the same preparation. The asterisk indicates significance $(p<0.001)$, comparing LTH with and without inhibitor by ANOVA and Dunnett's test. Error bars indicate SEM. 
in spike threshold and the increase in hyperexcitability were blocked by $\mathrm{Rp}-8$ pCPT-cGMPS, ODQ, and L-thiocitrulline, inhibitors of apPKG, sGC, and NOS, respectively (Fig. 6A,B,D). Moreover, Rp-8pCPT-cGMPS also caused a nearly threefold reduction in the level of apMAPK in the nucleus of the SNs (Fig. $8 \mathrm{~B}$ ). These findings pointed to a direct relationship between the activation of NOS and apPKG, the entry of apMAPK into the nucleus, and the induction of LTH. The finding that NOS mRNA expression in the SNs was increased after injury (Fig. 6C) implies that the level of NOS protein might be the rate-limiting step in the pathway. Neuronal NOS (nNOS) mRNA and protein expression also increase in DRG neurons after severing their peripheral axons (Verge et al., 1992; Fiallos-Estrada et al., 1993; Zhang et al., 1993).

cAMP and PKA have also been implicated in the induction and maintenance of LTH (Scholz and Byrne, 1988; Goldsmith and Abrams, 1992; Bedi et al., 1998), and this was a concern here because PKA and PKG have properties in common. However, we found that exposing the SNs to Rp-cAMPS, a membrane-permeable inhibitor of PKA, neither prevented the induction of LTH nor blocked apMAPK entry into the nucleus. This confirms previous findings that PKA inhibitors failed to block LTH induced by noxious stimulation (Lewin and Walters, 1999).

The activation of both apPKG and apMAPK by injury was intriguing, because it suggested a possible link between these two kinases (Zaragoza et al., 2002). Indeed, when we added active apPKG to a neuronal lysate, it not only activated apMAPK (Fig. 7B), but did so via a pathway that did not require MEK, the ubiquitous upstream activator of the ERKs. This response was physiologically relevant, because activated apMAPK phosphorylated its nuclear substrate Elk1 at the Ser $^{383}$ (Fig. 7C), which is essential for transcriptional activity (Marais et al., 1993; Whitmarsh et al., 1995). We established a direct interaction between the kinases when we incubated active apPKG with recombinant vertebrate ERK2, which has the same T-E-Y activation site as apMAPK, and found that the ERK2 was both activated (Fig. 7C) and doubly phosphorylated ( $D$, top). The latter finding indicated that the ERK2 was fully active, and this was supported by another study in which equal amounts of apPKG or MEK1 activated ERK2 to comparable levels (Fig. 7E).

The indications that apPKG produces a maximally activated ERK2 creates a paradox, because PKGs are serine-threonine
$\mathbf{A}$
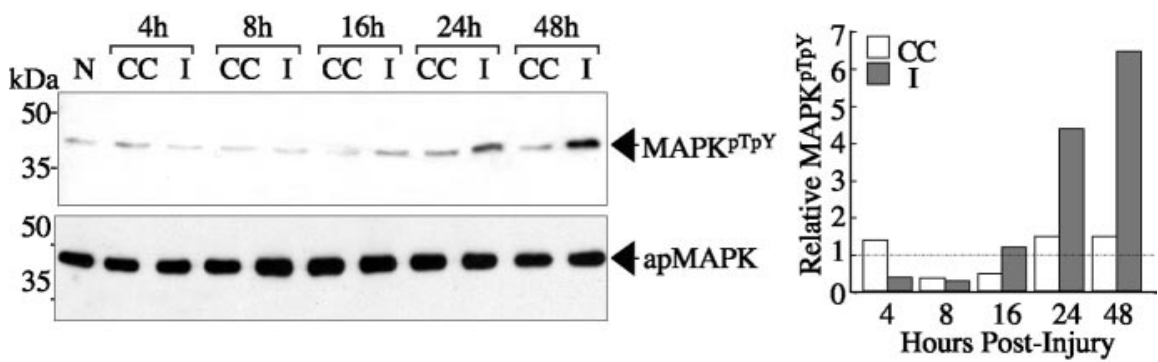

$\mathbf{B}$

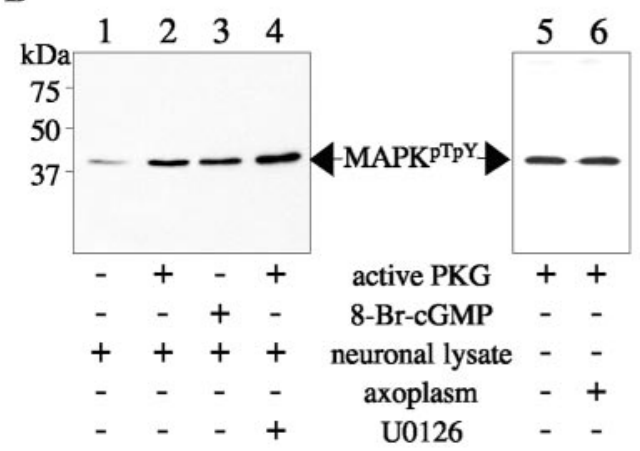

D
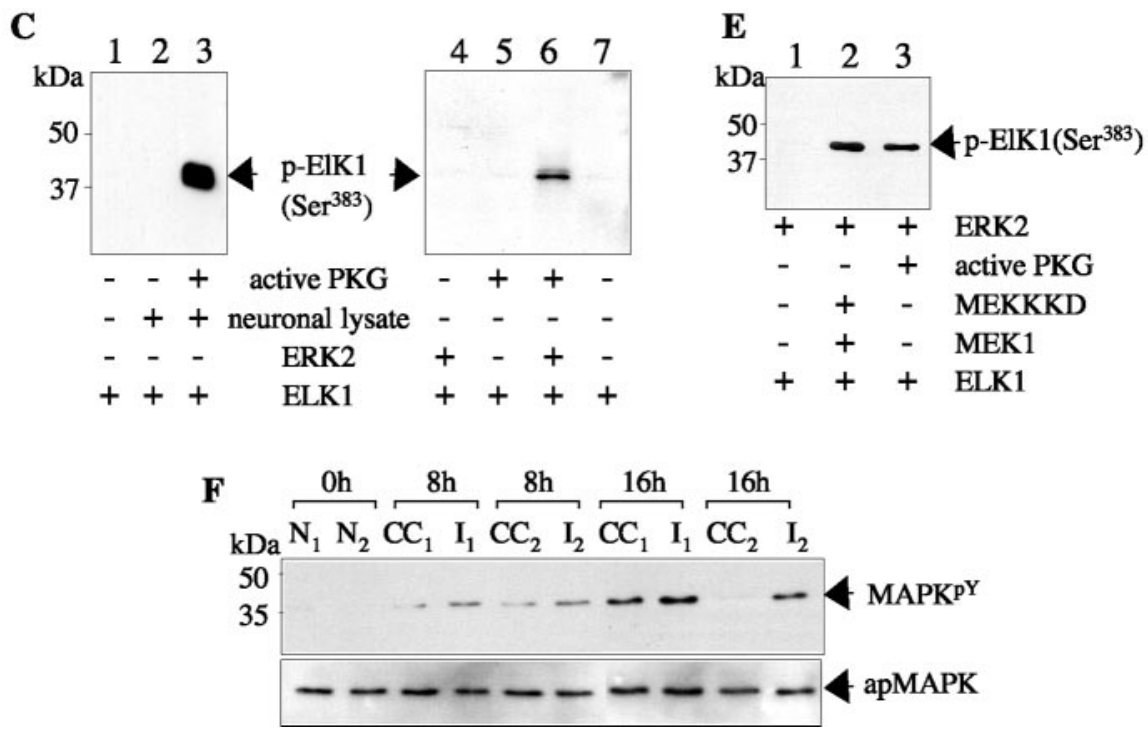

Figure 7. A, Activation of apMAPK in pleural ganglia after nerve crush. Top, Left, Twenty-five micrograms of a pleural ganglia lysate collected at the indicated times after $\mathrm{p5}-\mathrm{p} 9$ nerve crush were resolved by SDS-PAGE, and a Western blot was probed with $\mathrm{Ab}^{\mathrm{pTpYmapk}}$ to detect active ERK-MAPKs. The antibody recognized a $43 \mathrm{kDa}$ kinase whose activity was increased on the injured side (I) relative to the contralateral control (CC) $16 \mathrm{hr}$ and later after injury. Bottom, Left, The injury-activated kinase was apMAPK. The blot was stripped and probed with the D8 antibody, which recognizes both active and inactive apMAPK. D8 recognized the same $43 \mathrm{kDa}$ protein that was recognized by the $\mathrm{PTpY}$ antibody. Right, Relative MAPK ${ }^{\mathrm{PT} p}$ was determined by densitometry (Sung et al., 2003). All of the values were normalized to levels of total apMAPK. The ratio of the normalized MAPK ${ }^{\mathrm{PTPY}}$ intensity at each time to the normalized naive control is presented. The value for the naive control was arbitrarily set to 1.0. The Western analysis in this figure was performed with the same material used to assess apPKG activity in Figure $4 A$. The apMAPK values represent an average of six animals. The line indicates the basal level of apMAPK activity from naive animals. Each of the following experiments $(B-E)$ was repeated twice at least, and representative results are shown. $B$, apPKG phosphorylates endogenous apMAPK in neurons, but not axoplasm, in vitro. Left, Pleural neurons were removed from a noninjured animal, a lysate was prepared, and $25 \mu \mathrm{g}$ was incubated with $100 \mathrm{ng}$ of active apPKG protein or with $1 \mu \mathrm{m}$ 8-Br-cGMP in the presence or absence of $10 \mu \mathrm{m}$ U0126. Right, Twenty-five micrograms of axoplasm was incubated with active apPKG as above. Active apMAPK was detected by immunoblotting with Ab ${ }^{\text {pTpYmapk }}$. C, apPKG phosphorylates serine-383 in Elk1. One hundred nanograms of apPKG and $0.5 \mu \mathrm{g}$ of purified recombinant Elk1 protein were incubated with either $5 \mu \mathrm{g}$ of the pleural neuronal lysate or $0.2 \mu \mathrm{g}$ of purified recombinant ERK2. Phosphorylated Elk1 ( $p$-Elk1) was detected by probing a Western blot with an antibody that recognizes phosphorylated Ser ${ }^{383}$. D, Direct phosphorylation of ERK2 at T183 by apPKG. Two hundred nanograms of recombinant ERK2 was incubated with $100 \mathrm{ng}$ of apPKG in the presence or absence of $1 \mu \mathrm{g}$ of BPDEtide. The reaction mixture was divided into thirds, a Western blot of each was prepared, and ERK2 was detected with $\mathrm{Ab}^{\text {pTpYmapk }}$ (top), $\mathrm{Ab}^{\text {pYmapk }}$ (middle), and $\mathrm{Ab}^{\text {pTmapk }}$ (bottom), respectively. E, Relative activation of ERK2 by apPKG and MEK1. One hundred nanograms of apPKG, the catalytic subunit of MEKK1, and MEK1 were used (Figure legend continues.) 
$\mathbf{A}$

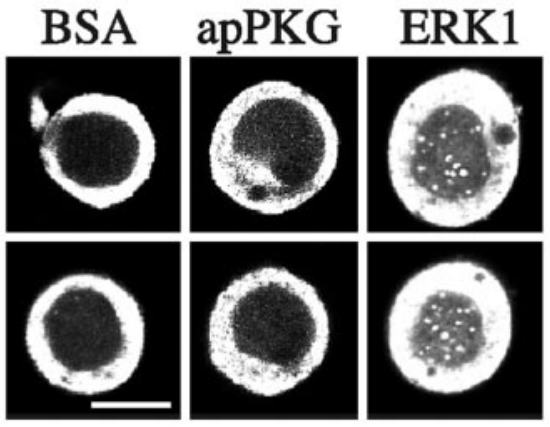

B
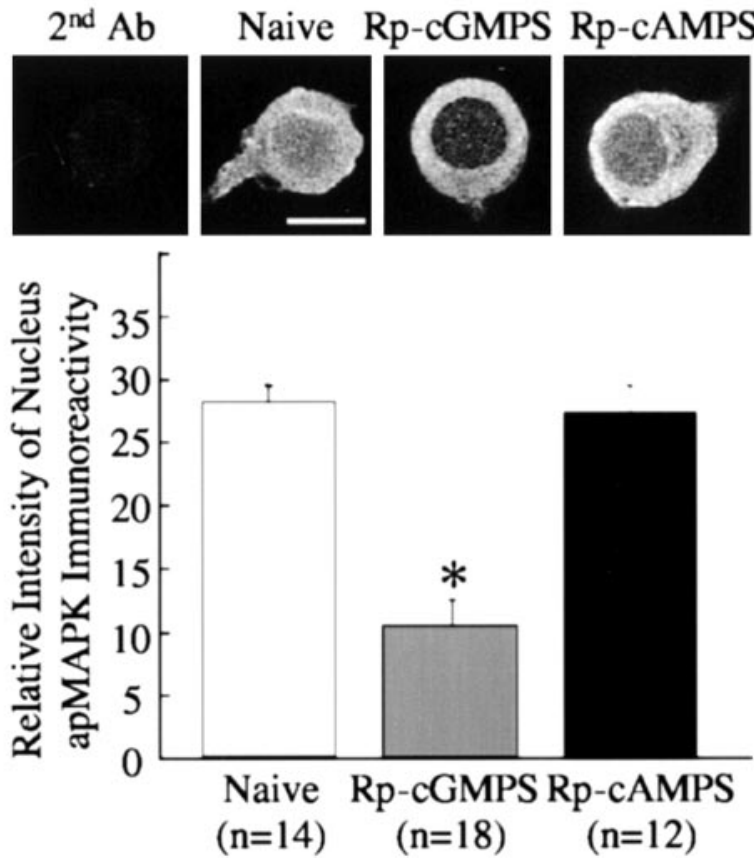

Figure 8. $\quad A$, apPKG does not enter the nucleus of SNs. Equal amounts of Alexa Fluor 546labeled BSA, apPKG, or ERK1 were microinjected into the cytoplasm of SNs after $2 \mathrm{~d}$ in vitro. The neurites were then severed with a fine needle to elicit an injury response, and $30 \mathrm{~min}$ later, the cells were examined by confocal microscopy. The image is a $2 \mu \mathrm{m}$ optical section through the center of the cell that shows the nucleus. Scale bar, $20 \mu \mathrm{m}$. B, Rp-8-pCPT-cGMPs inhibits axotomy-induced apMAPK nuclear translocation. SNs untreated as controls, and those exposed to either $10 \mu \mathrm{m}$ Rp-8-pCPT-cGMPs (Rp-cGMPs) or Rp-cAMPs for $2 \mathrm{~d}$ in vitro, were immunostained with D8 antibody to localize apMAPK. Top, Representative examples of $2 \mu \mathrm{m}$ optical sections of control SNs and those exposed to Rp-8-pCPT-cGMPs or Rp-cAMPs. Scale bar, $20 \mu \mathrm{m}$. Bottom, Histogram of the mean value of nuclear MAPKimmunoreactivity. The staining intensity was determined by a person who was blind to the treatment that the cells received. $n$, Number of cells for each treatment. Asterisk indicates significant difference from control ( $p<0.05$ by ANOVA and Newman-Keuls tests).

kinases that cannot phosphorylate the tyrosine. However, because the recombinant ERK2 already contains phospho-tyrosine185 (Fig. 7D, middle), the phosphorylation of threonine- 183 by apPKG (Fig. 7D, bottom) should produce a fully activated ERK2.

(Figure legend continued.) as indicated, and the production of phospho-Elk1 was measured with $\mathrm{Ab}^{\mathrm{pElk1}}$ as shown in C. F, Nerve injury increases the level of apMAPK ${ }^{\mathrm{PY}}$ in the cell soma of injured (I) relative to contralateral (CC) neurons. A Western blot prepared using $25 \mu \mathrm{g}$ of a pleural neuronal lysate collected at the indicated times after $\mathrm{p5}-\mathrm{p} 9$ nerve crush was probed with the monospecific $\mathrm{pY}$ antibody, Ab ${ }^{\text {PYmapk }}$, followed by D8 to detect total apMAPKas in A. The blot shows the results of two animals for each point. N, Lysate from animal without nerve crush.
The phosphorylation of apMAPK ${ }^{\mathrm{pY}}$ by apPKG is attractive, because ERK2 ${ }^{\mathrm{pY} 185}$ has been detected in vertebrate cells (Yao et al., 2000; Cha and Shapiro, 2001; Zhou and Zhang, 2002), and we have evidence that apMAPK ${ }^{\mathrm{PY}}$ expression increases in Aplysia neurons after nerve injury (Fig. $7 F$ ). apMAPK ${ }^{\mathrm{pY}}$ could be produced by a phosphatase that removes the phosphate from doubly phosphorylated apMAPK, or by an injury-activated tyrosine kinase that phosphorylates the tyrosine at the T-E-Y site. We are now determining which mechanism is correct. The possibility that the induction of LTH requires the convergence of apPKG and a tyrosine kinase on apMAPK would confer more control over this pathway. This is reasonable given that LTH radically alters the function of the injured neurons and leads to significant changes in the behavior of the animal.

apMAPK is also present in axoplasm, but is not activated by nerve injury (Sung et al., 2001; Lin et al., 2003), which is paradoxical, given that injury activates the axoplasmic apPKG. One explanation would be that the two kinases are located in different axons. However, when we added active apPKG to axoplasm extruded from the peripheral nerves, apMAPK was not activated under the same conditions that caused its activation in the cell soma (Fig. 7B). Evidently, there is a mechanism in the axon that shields apMAPK from apPKG. Nevertheless, these observations mean that, after its activation in the axon by injury, apPKG must be transported back to the soma to influence nuclear events via apMAPK.

\section{A working model for the induction of LTH}

We propose that nerve injury induces nNOS expression in the SNs. The nNOS is then activated in the axon, leading to NO production, resulting in the activation of sGC, the formation of cGMP, and the activation of apPKG. Activated apPKG is transported to the cell body of the SNs where it activates apMAPK ${ }^{\mathrm{pY}}$ in the cytoplasm, which then enters the nucleus. Although our findings strongly support this model, we have not completely excluded the possibility that nerve injury causes translocation of apMAPK or activation of somatic PKG by other pathways as well. An NO-cGMP-PKG-MAPK signaling pathway might also be important for LTH induced by the inflammation that develops around a nerve injury site, both in mammals (Millan, 1999; Zimmermann, 2001) and in Aplysia (Clatworthy et al., 1995; Clatworthy and Grose, 1999; Farr et al., 1999, 2001). How might nuclear apMAPK regulate LTH? apMAPK can phosphorylate CREB2 (cAMP response element-binding protein 2), a cAMP response element (CRE) site repressor (Bartsch et al., 1995; Michael et al., 1998), C/EBP (CCAAT/enhancer-binding protein), a transcription factor that binds to the estrogen response element (ERE) site (Alberini et al., 1994), and Elk1, a transcription factor that regulates the serum response element (SRE) site (Lin et al., 2003). Binding to all three sites increases after nerve injury, but with different time courses. Thus, binding of C/EBP and CREB to the ERE and CRE, respectively, is rapid, but relatively short lived (Dash et al., 1998; Sung et al., 2001), whereas the binding of Elk1 to the SRE is biphasic, with an early phase that lasts for a few hours and a second phase that persists for weeks (Lin et al., 2003). CREB is phosphorylated in DRG neurons in response to intense activity ( $\mathrm{Ji}$ and Woolf, 2001), and the CRE site is required for the LTH response to noxious stimuli in Aplysia SNs (Lewin and Walters, 1999). Based on these considerations, we propose that CREB2 and C/EBP are the targets of apMAPK during the initial induction of 
the LTH in the SNs, and that the persistence of LTH for weeks is mediated by the phosphorylation of Elk1 by apMAPK. This pathway is selective, because inhibiting NOS, sGC, or PKG prevented the appearance of LTH in dissociated SNs, but did not block growth. If the link between this pathway and LTH represents a fundamental, widely conserved relationship, then therapeutic interventions that target this pathway might mitigate persistent pain after nerve injury without blocking axon regeneration.

\section{References}

Abdulla FA, Smith PA (2001) Axotomy- and autotomy-induced changes in the excitability of rat dorsal root ganglion neurons. J Neurophysiol 85:630-643.

Alberini CM, Ghirardi M, Metz R, Kandel ER (1994) C/EBP is an immediate-early gene required for the consolidation of long-term facilitation in Aplysia. Cell 76:1099-1114.

Ambron RT, Walters ET (1996) Priming events and retrograde injury signals. A new perspective on the cellular and molecular biology of nerve regeneration. Mol Neurobiol 13:61-79.

Ambron RT, Schmied R, Huang CC, Smedman M (1992) A signal sequence mediates the retrograde transport of proteins from the axon periphery to the cell body and then into the nucleus. J Neurosci 12:2813-2818.

Ambron RT, Dulin MF, Zhang XP, Schmied R, Walters ET (1995) Axoplasm enriched in a protein mobilized by nerve injury induces memorylike alterations in Aplysia neurons. J Neurosci 15:3440-3446.

Ambron RT, Zhang XP, Gunstream JD, Povelones M, Walters ET (1996) Intrinsic injury signals enhance growth, survival, and excitability of Aplysia neurons. J Neurosci 16:7469-7477.

Antonov I, Antonova I, Kandel ER, Hawkins RD (2003) Activity-dependent presynaptic facilitation and hebbian LTP are both required and interact during classical conditioning in Aplysia. Neuron 37:135-147.

Bartsch D, Ghirardi M, Skehel PA, Karl KA, Herder SP, Chen M, Bailey CH, Kandel ER (1995) Aplysia CREB2 represses long-term facilitation: relief of repression converts transient facilitation into long-term functional and structural change. Cell 83:979-992.

Bedi SS, Salim A, Chen S, Glanzman DL (1998) Long-term effects of axotomy on excitability and growth of isolated Aplysia sensory neurons in cell culture: potential role of cAMP. J Neurophysiol 79:1371-1383.

Billy AJ, Walters ET (1989) Long-term expansion and sensitization of mechanosensory receptive fields in Aplysia support an activity-dependent model of whole-cell sensory plasticity. J Neurosci 9:1254-1262.

Bredt DS, Snyder SH (1990) Isolation of nitric oxide synthetase, a calmodulin-requiring enzyme. Proc Natl Acad Sci USA 87:682-685.

Brunet JF, Shapiro E, Foster SA, Kandel ER, Iino Y (1991) Identification of a peptide specific for Aplysia sensory neurons by PCR-based differential screening. Science 252:856-859.

Byrne JH, Kandel ER (1996) Presynaptic facilitation revisited: state and time dependence. J Neurosci 16:425-435.

Cha H, Shapiro P (2001) Tyrosine-phosphorylated extracellular signalregulated kinase associates with the Golgi complex during $\mathrm{G}_{2} / \mathrm{M}$ phase of the cell cycle: evidence for regulation of Golgi structure. J Cell Biol 153:1355-1367.

Chain DG, Casadio A, Schacher S, Hegde AN, Valbrun M, Yamamoto N, Goldberg AL, Bartsch D, Kandel ER, Schwartz JH (1999) Mechanisms for generating the autonomous cAMP-dependent protein kinase required for long-term facilitation in Aplysia. Neuron 22:147-156.

Chen Y, Devor M (1998) Ectopic mechanosensitivity in injured sensory axons arises from the site of spontaneous electrogenesis. Eur J Pain 2:165-178.

Clatworthy AL, Grose E (1999) Immune-mediated alterations in nociceptive sensory function in Aplysia californica. J Exp Biol 202:623-630.

Clatworthy AL, Illich PA, Castro GA, Walters ET (1995) Role of peri-axonal inflammation in the development of thermal hyperalgesia and guarding behavior in a rat model of neuropathic pain. Neurosci Lett 184:5-8.

Dagan D, Levitan IB (1981) Isolated identified Aplysia neurons in cell culture. J Neurosci 1:736-740.

Dale N, Schacher S, Kandel ER (1988) Long-term facilitation in Aplysia involves increase in transmitter release. Science 239:282-285.

Dash PK, Tian LM, Moore AN (1998) Sequestration of cAMP response element-binding proteins by transcription factor decoys causes collateral elaboration of regenerating Aplysia motor neuron axons. Proc Natl Acad Sci USA 95:8339-8344.

DesGroseillers L, Auclair D, Wickham L, Maalouf M (1994) A novel actin cDNA is expressed in the neurons of Aplysia californica. Biochim Biophys Acta 1217:322-324.

Farr M, Mathews J, Zhu DF, Ambron RT (1999) Inflammation causes a long-term hyperexcitability in the nociceptive sensory neurons of Aplysia. Learn Mem 6:331-340.

Farr M, Zhu DF, Povelones M, Valcich D, Ambron RT (2001) Direct interactions between immunocytes and neurons after axotomy in Aplysia. J Neurobiol 46:89-96.

Fiallos-Estrada CE, Kummer W, Mayer B, Bravo R, Zimmermann M, Herdegen $T$ (1993) Long-lasting increase of nitric oxide synthase immunoreactivity, NADPH-diaphorase reaction and c-JUN co-expression in rat dorsal root ganglion neurons following sciatic nerve transection. Neurosci Lett 150:169-173.

Francis SH, Corbin JD (1994) Structure and function of cyclic nucleotidedependent protein kinases. Annu Rev Physiol 56:237-272.

Ghirardi M, Braha O, Hochner B, Montarolo PG, Kandel ER, Dale N (1992) Roles of PKA and PKC in facilitation of evoked and spontaneous transmitter release at depressed and nondepressed synapses in Aplysia sensory neurons. Neuron 9:479-489.

Glanzman DL, Kandel ER, Schacher S (1989) Identified target motor neuron regulates neurite outgrowth and synapse formation of Aplysia sensory neurons in vitro. Neuron 3:441-450.

Glass DB, Krebs EG (1982) Phosphorylation by guanosine $3^{\prime}: 5^{\prime}$ monophosphate-dependent protein kinase of synthetic peptide analogs of a site phosphorylated in histone H2B. J Biol Chem 257:1196-1200.

Goldsmith BA, Abrams TW (1992) cAMP modulates multiple $\mathrm{K}^{+}$currents, increasing spike duration and excitability in Aplysia sensory neurons. Proc Natl Acad Sci USA 89:11481-11485.

Gracely RH, Lynch SA, Bennett GJ (1992) Painful neuropathy: altered central processing maintained dynamically by peripheral input. Pain 51:175-194.

Gudi T, Lohmann SM, Pilz RB (1997) Regulation of gene expression by cyclic GMP-dependent protein kinase requires nuclear translocation of the kinase: identification of a nuclear localization signal. Mol Cell Biol 17:5244-5254.

Gunstream JD, Castro GA, Walters ET (1995) Retrograde transport of plasticity signals in Aplysia sensory neurons following axonal injury. J Neurosci 15:439-448.

Hall KU, Collins SP, Gamm DM, Massa E, DePaoli-Roach AA, Uhler MD (1999) Phosphorylation-dependent inhibition of protein phosphatase-1 by G-substrate. A Purkinje cell substrate of the cyclic GMP-dependent protein kinase. J Biol Chem 274:3485-3495.

Hanz S, Perlson E, Willis D, Zheng JQ, Massarwa R, Huerta JJ, Koltzenburg M, Kohler M, van-Minnen J, Twiss JL, Fainzilber M (2003) Axoplasmic importins enable retrograde injury signaling in lesioned nerve. Neuron 40:1095-1104.

Ji RR, Woolf CJ (2001) Neuronal plasticity and signal transduction in nociceptive neurons: implications for the initiation and maintenance of pathological pain. Neurobiol Dis 8:1-10.

Johanson SO, Crouch MF, Hendry IA (1995) Retrograde axonal transport of signal transduction proteins in rat sciatic nerve. Brain Res 690:55-63.

Karin M (1994) Signal transduction from the cell surface to the nucleus through the phosphorylation of transcription factors. Curr Opin Cell Biol 6:415-424.

Kim YI, Na HS, Kim SH, Han HC, Yoon YW, Sung B, Nam HJ, Shin SL, Hong SK (1998) Cell type-specific changes of the membrane properties of peripherally-axotomized dorsal root ganglion neurons in a rat model of neuropathic pain. Neuroscience 86:301-309.

Lewin MR, Walters ET (1999) Cyclic GMP pathway is critical for inducing long-term sensitization of nociceptive sensory neurons. Nat Neurosci 2:18-23.

Liao X, Gunstream JD, Lewin MR, Ambron RT, Walters ET (1999) Activation of protein kinase A contributes to the expression but not the induction of long-term hyperexcitability caused by axotomy of Aplysia sensory neurons. J Neurosci 19:1247-1256.

Lin H, Bao J, Sung YJ, Walters ET, Ambron RT (2003) Rapid electrical and delayed molecular signals regulate the serum response element after nerve injury: convergence of injury and learning signals. J Neurobiol $57: 204-220$. 
Marais R, Wynne J, Treisman R (1993) The SRF accessory protein Elk-1 contains a growth factor-regulated transcriptional activation domain. Cell 73:381-393.

Martin KC, Michael D, Rose JC, Barad M, Casadio A, Zhu H, Kandel ER (1997) MAP kinase translocates into the nucleus of the presynaptic cell and is required for long-term facilitation in Aplysia. Neuron 18:899-912.

Michael D, Martin KC, Seger R, Ning MM, Baston R, Kandel ER (1998) Repeated pulses of serotonin required for long-term facilitation activate mitogen-activated protein kinase in sensory neurons of Aplysia. Proc Natl Acad Sci USA 95:1864-1869.

Millan MJ (1999) The induction of pain: an integrative review. Prog Neurobiol 57:1-164.

Monfort P, Munoz MD, Kosenko E, Felipo V (2002) Long-term potentiation in hippocampus involves sequential activation of soluble guanylate cyclase, cGMP-dependent protein kinase, and cGMP-degrading phosphodiesterase. J Neurosci 22:10116-10122.

Moroz LL, Chen D, Gillette MU, Gillette R (1996) Nitric oxide synthase activity in the molluscan CNS. J Neurochem 66:873-876.

Muller U, Carew TJ (1998) Serotonin induces temporally and mechanistically distinct phases of persistent PKA activity in Aplysia sensory neurons. Neuron 21:1423-1434.

Park SY, Choi JY, Kim RU, Lee YS, Cho HJ, Kim DS (2003) Downregulation of voltage-gated potassium channel $\alpha$ gene expression by axotomy and neurotrophins in rat dorsal root ganglia. Mol Cells 16:256-259.

Pohler D, Butt E, Meissner J, Muller S, Lohse M, Walter U, Lohmann SM, Jarchau T (1995) Expression, purification, and characterization of the cGMP-dependent protein kinases I $\beta$ and II using the baculovirus system. FEBS Lett 374:419-425.

Schlossmann J, Feil R, Hofmann F (2003) Signaling through NO and cGMP-dependent protein kinases. Ann Med 35:21-27.

Schmied R, Ambron RT (1997) A nuclear localization signal targets proteins to the retrograde transport system, thereby evading uptake into organelles in Aplysia axons. J Neurobiol 33:151-160.

Schmied R, Huang CC, Zhang XP, Ambron DA, Ambron RT (1993) Endogenous axoplasmic proteins and proteins containing nuclear localization signal sequences use the retrograde axonal transport/nuclear import pathway in Aplysia neurons. J Neurosci 13:4064-4071.

Scholz KP, Byrne JH (1988) Intracellular injection of cAMP induces a longterm reduction of neuronal $\mathrm{K}^{+}$currents. Science 240:1664-1666.

Scott JD (1991) Cyclic nucleotide-dependent protein kinases. Pharmacol Ther 50:123-145.

Smolenski A, Bachmann C, Reinhard K, Honig-Liedl P, Jarchau T, Hoschuetzky H, Walter U (1998) Analysis and regulation of vasodilatorstimulated phosphoprotein serine 239 phosphorylation in vitro and in intact cells using a phosphospecific monoclonal antibody. J Biol Chem 273:20029-20035.

Study RE, Kral MG (1996) Spontaneous action potential activity in isolated dorsal root ganglion neurons from rats with a painful neuropathy. Pain 65:235-242.

Sung YJ, Ambron RT (2004) Pathways that elicit long-term changes in gene expression in nociceptive neurons following nerve injury: contributions to neuropathic pain. Neurol Res 26:195-203.

Sung YJ, Hwang MC, Hwang YW (1996) The dominant negative effects of H-Ras harboring a Gly to Ala mutation at position 60. J Biol Chem 271:30537-30543.

Sung YJ, Conti J, Currie JR, Brown WT, Denman RB (2000) RNAs that interact with the fragile $\mathrm{X}$ syndrome RNA binding protein FMRP. Biochem Biophys Res Commun 275:973-980.

Sung YJ, Povelones M, Ambron RT (2001) RISK-1: a novel MAPK homologue in axoplasm that is activated and retrogradely transported after nerve injury. J Neurobiol 47:67-79.

Sung YJ, Dolzhanskaya N, Nolin SL, Brown T, Currie JR, Denman RB (2003) The fragile $\mathrm{X}$ mental retardation protein FMRP binds elongation factor
1A mRNA and negatively regulates its translation in vivo. J Biol Chem 278:15669-15678.

Sutton MA, Carew TJ (2000) Parallel molecular pathways mediate expression of distinct forms of intermediate-term facilitation at tail sensorymotor synapses in Aplysia. Neuron 26:219-231.

Ungless MA, Gasull X, Walters ET (2002) Long-term alteration of S-type potassium current and passive membrane properties in Aplysia sensory neurons following axotomy. J Neurophysiol 87:2408-2420.

Verge VM, Xu Z, Xu XJ, Wiesenfeld-Hallin Z, Hokfelt T (1992) Marked increase in nitric oxide synthase mRNA in rat dorsal root ganglia after peripheral axotomy: in situ hybridization and functional studies. Proc Natl Acad Sci USA 89:11617-11621.

Wall PD, Devor M (1983) Sensory afferent impulses originate from dorsal root ganglia as well as from the periphery in normal and nerve injured rats. Pain 17:321-339.

Walters ET (1994) Injury-related behavior and neuronal plasticity: an evolutionary perspective on sensitization, hyperalgesia, and analgesia. Int Rev Neurobiol 36:325-427.

Walters ET, Byrne JH, Carew TJ, Kandel ER (1983a) Mechanoafferent neurons innervating tail of Aplysia. I. Response properties and synaptic connections. J Neurophysiol 50:1522-1542.

Walters ET, Byrne JH, Carew TJ, Kandel ER (1983b) Mechanoafferent neurons innervating tail of Aplysia. II. Modulation by sensitizing stimulation. J Neurophysiol 50:1543-1559.

Walters ET, Alizadeh H, Castro GA (1991) Similar neuronal alterations induced by axonal injury and learning in Aplysia. Science 253:797-799.

Walters ET, Bodnarova M, Billy AJ, Dulin MF, Diaz-Rios M, Miller MW, Moroz LL (2004) Somatotopic organization and functional properties of mechanosensory neurons expressing sensorin-A mRNA in Aplysia californica. J Comp Neurol 471:219-240.

Wang H, Sun H, Della Penna K, Benz RJ, Xu J, Gerhold DL, Holder DJ, Koblan KS (2002) Chronic neuropathic pain is accompanied by global changes in gene expression and shares pathobiology with neurodegenerative diseases. Neuroscience 114:529-546.

Waxman SG, Kocsis JD, Black JA (1994) Type III sodium channel mRNA is expressed in embryonic but not adult spinal sensory neurons, and is reexpressed following axotomy. J Neurophysiol 72:466-470.

Whitmarsh AJ, Shore P, Sharrocks AD, Davis RJ (1995) Integration of MAP kinase signal transduction pathways at the serum response element. Science 269:403-407.

Xu S, Robbins D, Frost J, Dang A, Lange-Carter C, Cobb MH (1995) MEKK1 phosphorylates MEK1 and MEK2 but does not cause activation of mitogenactivated protein kinase. Proc Natl Acad Sci USA 92:6808-6812.

Yao Z, Dolginov Y, Hanoch T, Yung Y, Ridner G, Lando Z, Zharhary D, Seger R (2000) Detection of partially phosphorylated forms of ERK by monoclonal antibodies reveals spatial regulation of ERK activity by phosphatases. FEBS Lett 468:37-42.

Zaragoza C, Soria E, Lopez E, Browning D, Balbin M, Lopez-Otin C, Lamas S (2002) Activation of the mitogen activated protein kinase extracellular signal-regulated kinase 1 and 2 by the nitric oxide-cGMP-cGMPdependent protein kinase axis regulates the expression of matrix metalloproteinase 13 in vascular endothelial cells. Mol Pharmacol 62:927-935.

Zhang JM, Donnelly DF, Song XJ, Lamotte RH (1997) Axotomy increases the excitability of dorsal root ganglion cells with unmyelinated axons. J Neurophysiol 78:2790-2794.

Zhang X, Verge V, Wiesenfeld-Hallin Z, Ju G, Bredt D, Synder SH, Hokfelt T (1993) Nitric oxide synthase-like immunoreactivity in lumbar dorsal root ganglia and spinal cord of rat and monkey and effect of peripheral axotomy. J Comp Neurol 335:563-575.

Zhou B, Zhang ZY (2002) The activity of the extracellular signal-regulated kinase 2 is regulated by the differential phosphorylation in the activation loop. J. Biol Chem 277:13889-13899.

Zimmermann M (2001) Pathobiology of neuropathic pain. Eur J Pharmacol 429:23-37. 